DIW BERLIN

Discussion

Papers
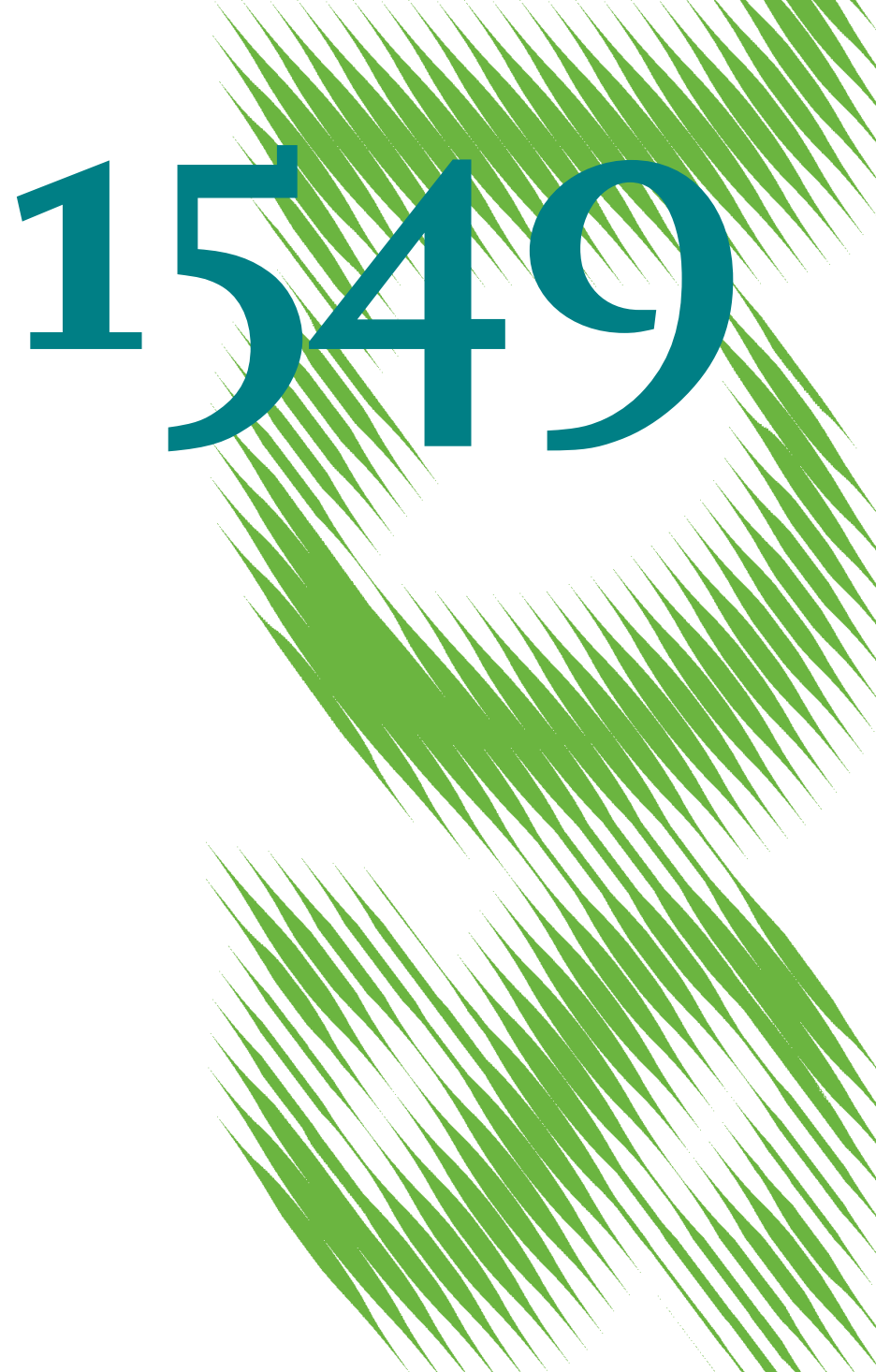

Identifying Uncertainty Shocks

Using the Price of Gold 
Opinions expressed in this paper are those of the author(s) and do not necessarily reflect views of the institute.

IMPRESSUM

(C) DIW Berlin, 2016

DIW Berlin

German Institute for Economic Research

Mohrenstr. 58

10117 Berlin

Tel. +49 (30) $89789-0$

Fax +49 (30) $89789-200$

http://www.diw.de

ISSN electronic edition 1619-4535

Papers can be downloaded free of charge from the DIW Berlin website:

http://www.diw.de/discussionpapers

Discussion Papers of DIW Berlin are indexed in RePEc and SSRN:

http://ideas.repec.org/s/diw/diwwpp.html

http://www.ssrn.com/link/DIW-Berlin-German-Inst-Econ-Res.html 


\title{
Identifying Uncertainty Shocks Using the Price of Gold*
}

\author{
Michele Piffer and Maximilian Podstawski ${ }^{\dagger}$
}

February 11, 2016

\begin{abstract}
We propose a new instrument to identify the impact of uncertainty shocks in a SVAR model with external instruments. We construct the instrument for uncertainty shocks by exploiting variations in the price of gold around selected events. The events capture periods of changes in uncertainty unrelated to other macroeconomic shocks. The variations in the price of gold around such events provide a measure correlated with the underlying uncertainty shocks, due to the perception of gold as a safe haven asset. The proposed approach improves upon the recursive identification of uncertainty shocks by not restricting only one structural shock to potentially affect all variables in the system. Replicating Bloom (2009), we find that the recursive approach underestimates the effects of uncertainty shocks and their role in driving monetary policy.
\end{abstract}

JEL classification: E32, C32, D81.

Keywords: Economic uncertainty, external proxy SVAR, safe haven assets.

${ }^{*}$ We are thankful to participants to a seminar at the Bank of Italy and a seminar at Freie Universität Berlin, together with Christoph Große Steffen, Michael Hachula, Helmut Lütkepohl, Jonathan Pinder, David Pothier, Morten Ravn and Malte Rieth, for insightful discussions and helpful comments to this paper. Many thanks to Moritz Leitner for excellent research assistance. We also thank Alex Pop for sharing his knowledge of the London Bullion Market.

${ }^{\dagger}$ Michele Piffer: German Institute for Economic Research (DIW Berlin); e-mail: m.b.piffer@gmail.com. Maximilian Podstawski: German Institute for Economic Research (DIW Berlin) and Freie Universität Berlin; e-mail: mpodstawski@diw.de. 


\section{Introduction}

Economic uncertainty, broadly defined as the difficulty of economic agents to make accurate forecasts (Bloom, 2014; Jurado et al., 2015), is widely believed to have potentially far reaching implications for the economy. Nevertheless, identifying the impact of uncertainty on the economy is challenging, because uncertainty and the economy are determined simultaneously. Since Bloom (2009), this challenge has been addressed in the economic literature by developing strategies to identify uncertainty shocks, and to estimate the impact of such shocks on the economy.

The economic impact of uncertainty shocks has been largely studied using Vector Autoregressive (VAR) models. Their identification largely relies on the use of the recursive approach (see, among others, Bloom, 2009; Baker et al., 2013; Scotti, 2013; Bachmann et al., 2013; Caggiano et al., 2014; Jurado et al., 2015). Nevertheless, the exclusion restrictions implied by the recursive identification have received substantial criticism, because they impose that no other structural shock contemporaneously affects the variables affected contemporaneously by the uncertainty shock (see Stock and Watson, 2012; Baker and Bloom, 2013).

In this paper we propose a new strategy for the identification of uncertainty shocks. We make use of the proxy SVAR methodology developed by Stock and Watson (2012) and Mertens and Ravn (2013) to identify structural VARs using external instruments and propose a new instrument for the identification of uncertainty shocks. In their investigation of the macroeconomic dynamics of the great recession, Stock and Watson (2012) highlight the challenge in isolating exogenous variations in uncertainty. This paper attempts to fill this gap.

The identification strategy proposed in this paper relies on the dynamics of the price of safe haven assets around selected events. It is reasonable to presume that events generating unexpected variations in uncertainty are reflected in the price of assets perceived by market participants as safe havens. For example, an increase in uncertainty due to, say, an event that caused significant geopolitical instability might 
materialize in a jump in the price of a safe haven asset. This could happen because agents respond to the higher uncertainty by rebalancing their investments toward the safe asset, or because those who hold such an asset are less willing to sell it, or both. Accordingly, the price of safe haven assets can be a useful point of departure to build an identification strategy for uncertainty shocks.

Since the price of a safe asset does not only reflect uncertainty shocks but also many other structural shocks, not all variations in the price of safe assets can be used to isolate uncertainty shocks. For this reason, we exploit the variation in the price of safe assets around specific events. We consider events associated with variations in uncertainty that occurred in an exogenous way relative to the state of the economy. For example, we use the 9/11 terrorist attack to the World Trade Center, the invasion of Kuwait by Iraq, the Chernobyl nuclear disaster and the fall of the Berlin Wall. The use of events to isolate exogenous variations in variables of interest has a longstanding tradition in the literature (see, for instance, Kuttner, 2001; Gurkaynak et al., 2005). Having selected events that exogenously varied uncertainty, we construct an instrument (or proxy) for uncertainty shocks by measuring the variation of the price of safe haven assets around the events. While not measuring the shocks themselves, these variations reflect the response of agents to the underlying uncertainty shocks, and hence are correlated with such shocks, a feature that we exploit to construct of an instrument. A battery of tests suggests using the price of gold to construct the proxy, out of a wide range of candidate assets considered. For the price of gold, we use intradaily data from the London Bullion Market, and Bloomberg News to address when the news of each event hit the market.

The identification used in the paper has three main advantages. Firstly, it allows for contemporaneous effects of the uncertainty shock on all variables, while not restricting the uncertainty shock to be the only shock that potentially affects contemporaneously all variables. Secondly, it permits to build the identification approach on high frequency data, instead of relying on monthly data as with identifications pursued 
within the VAR model itself. Thirdly, it allows to explicitly account for possible measurement errors in the construction of the proxy for uncertainty shocks - a feature that is particularly well-tailored given the approximative nature of uncertainty measures in general.

We compare the effects of an uncertainty shock identified via the proposed proxy SVAR with the effects identified via the popular recursive approach. We find that in the proxy SVAR, the uncertainty shock (1) triggers an instantaneous reaction of the financial market variables, (2) exhibits a larger response of the real economy with a subsequent overshooting as predicted by the model in Bloom (2009), and (3) is followed by a significant and prolonged monetary policy response. In addition, the uncertainty shock identified in the proxy SVAR explains a larger share in the variance of the real variables, while the fraction explained by the recursively identified shock is rather small.

The paper relates to the literature concerned with estimating the effects of uncertainty shocks on real and financial variables. One strand of the literature investigates uncertainty shocks as a potential driver of the business cycle. ${ }^{1}$ Another (complementary) strand of the literature focuses on developing and refining measures of economic uncertainty. $^{2}$ Others take a Bayesian approach to the interpretation of uncertainty. ${ }^{3}$ In this paper we do not aim at constructing a potential measure of uncertainty, but draw inference on the exogenous variations of uncertainty in a proxy SVAR setup.

There are other papers that propose identification approaches differing from the recursive one. Alessandri and Mumtaz (2014) identify uncertainty shocks in a VAR as the exogenous variations to a variable that scales the variance-covariance matrix of the structural shocks. Caldara et al. (2014) identify uncertainty and financial shocks as the ones that have the highest impact on the measure of uncertainty and on the financial

\footnotetext{
${ }^{1}$ For example Leahy and Whited (1996); Bloom et al. (2007).

${ }^{2}$ For example Dovern et al. (2012); Mankiw et al. (2003); Baker et al. (2013); Scotti (2013); Jurado et al. (2015); Rossi and Sekhposyan (2015); Bachmann et al. (2013).

${ }^{3}$ For example Orlik and Veldkamp (2014).
} 
variable in the VAR, respectively. Cesa-Bianchi et al. (2014) identify uncertainty shocks as the common stochastic component to the VIX index in several countries. Ludvigson et al. (2015) identify macroeconomic and financial uncertainty shocks using an iterative statistical approach on stock market data.

We are aware of two papers closest to our paper. Baker and Bloom (2013) use dummy variables constructed on extreme events as instrument in a single equation model of GDP growth on uncertainty. Using a VAR, we explore, instead, the endogenous dynamic response of the economy. Carriero et al. (2015) also make use of a proxy SVAR setup for the identification of uncertainty shocks. As a proxy they use a dummy variable taking value 1 when the VXO peaks, and then employ a Monte Carlo to study the effect of measurement errors on the estimation of impulse responses. We improve upon these papers by using a proxy variable that is not restricted to a dummy variable. To the best of our knowledge, our paper is the first one to study uncertainty shocks using the dynamics of the price of a safe asset around selected events.

The remainder of the paper is structured as follows. The next section discusses the identification via external instruments in the proxy SVAR setup. Section 3 introduces the construction of the proxy for uncertainty shocks used to identify the VAR model. Section 4 discusses the model specification and the data. Section 5 reports the results and relates them to the literature. Finally, Section 6 concludes.

\section{The proxy SVAR model}

Before discussing the construction of the proxy, we introduce the framework for the identification of structural VARs via external instruments and highlight the requirements that the instrument will need to satisfy.

Let the reduced form model be given by

$$
\boldsymbol{y}_{t}=\boldsymbol{\delta}+A(L) \boldsymbol{y}_{t-1}+\boldsymbol{u}_{t}
$$


In equation (1), $\boldsymbol{y}_{t}$ is an $K \times 1$ vector including the endogenous variables, $\boldsymbol{\delta}$ includes constant terms and $A(L)$ is a lag matrix polynomial capturing the autoregressive component of the model. The reduced form shocks captured by the $K \times 1$ vector $\boldsymbol{u}_{t}$ are assumed to be linearly related to the underlying structural shocks through the equation

$$
\boldsymbol{u}_{t}=B \boldsymbol{\epsilon}_{t}
$$

where $\boldsymbol{\epsilon}_{t}$ is an $K \times 1$ vector of structural shocks, whose variance-covariance matrix is normalized to the identity matrix.

We aim to identify the uncertainty shock out of the $K$ structural shocks in $\boldsymbol{\epsilon}_{t}$. Let the scalar $\epsilon_{t}^{u}$ be the uncertainty shock and let the vector $\epsilon_{t}^{*}$ be the other structural shocks. Under the recursive approach, identifying $\epsilon_{t}^{u}$ consists of first obtaining the Cholesky decomposition of the variance-covariance matrix of the reduced form shocks, and then selecting the column vector corresponding to the measure of uncertainty in $\boldsymbol{y}_{t}$. Instead, under the proxy SVAR identification proposed by Stock and Watson (2012) and Mertens and Ravn (2013) and used in this paper, identifying $\epsilon_{t}^{u}$ consists of estimating the column vector $\boldsymbol{b}^{u}$ that captures the correlation between the reduced form shocks and the proxy of uncertainty shocks (the position of this vector in the $B$ matrix is irrelevant). To do so, one needs a valid instrument for $\epsilon_{t}^{u}$.

Let us start from the statistical requirements that a valid instrument, $m_{t}$, needs to satisfy for the estimator to deliver consistent estimates of $\boldsymbol{b}^{u}$. Formally, given $\boldsymbol{u}_{t}=\boldsymbol{b}^{u} \epsilon_{t}^{u}+B^{*} \boldsymbol{\epsilon}_{t}^{*}$, the requirements for $m_{t}$ are

$$
\begin{aligned}
& E\left(m_{t} \epsilon_{t}^{u}\right) \neq 0, \\
& E\left(m_{t} \boldsymbol{\epsilon}_{t}^{*}\right)=\mathbf{0} .
\end{aligned}
$$

Intuitively the validity of the instruments requires that the instrument is at the same time correlated with the shock of interest, i.e. relevant (equation (2)), and uncorrelated with the remaining shocks, i.e. exogenous (equation (3)). There is no need for 
the instrument to capture the uncertainty shock perfectly, it only needs to reflect contemporaneous variations of it and not contemporaneous variations of other structural shocks. In principle, the instrument could still be correlated with other structural shocks in lags and leads, as long as not contemporaneously. In addition, the instrument does not need to be symmetric around zero, cover the entire time length covered by the VAR model nor take non-zero values at every period covered. In Section 3, this will imply that the proxy may, and in fact does, cover increases in uncertainty more frequently than decreases, be available for a shorter period relative to the period used for the estimation of the VAR, and take values only for some of the months. It is this ability to deal with several forms of measurement errors that makes the identification of structural VARs with external instruments particularly robust.

The relevance and exogeneity conditions for the proxy are fundamentally nontestable. ${ }^{4}$ What can be tested, instead, is the strength of the instrument, and we will use this test as one of the tests to discriminate between candidate instruments. This test requires $m_{t}$ to be sufficiently correlated with the reduced form shocks $\boldsymbol{u}_{t}$, in particular, with the reduced form shock of the equation of the VAR which features the measure of uncertainty as dependent variable. Intuitively, the instrument needs to be sufficiently related to the reduced form shocks because it is from these innovations that we aim to learn about the impulse vector $\boldsymbol{b}^{u}$. Formally, call $\hat{u}_{i, t}$ the estimated reduced form shock in equation $i$ at time $t$. We test the strength of the instrument from the statistical significance of the parameter $\beta_{i}$ in the regressions

$$
\hat{u}_{i, t}=\alpha+\beta_{i} \cdot m_{t}+\eta_{i, t} \quad, \quad i=1,2, \ldots, K .
$$

Having discussed the requirements that $m_{t}$ needs to meet, we now discuss how we compute the proxy for the uncertainty shocks.

\footnotetext{
${ }^{4}$ This is in contrast to the standard application of instrumental variable estimation, where the validity of the instruments can be tested as the relationship between the instrument and the endogenous regressor.
} 


\section{A proxy for uncertainty shocks}

The construction of the proxy variable is based upon two steps. Firstly, we collect an array of events that potentially affected economic uncertainty in an unrelated way with respect to other macroeconomic shocks. Secondly, we use variations in the prices of an array of safe haven assets to inform the proxy around the selected events.

\subsection{Collecting the events}

To isolate periods in which uncertainty is likely to have changed exogenously with respect to the economy, we collect a vector of events that potentially generated or reduced uncertainty, that were not anticipated, and that were exogenous with respect to other relevant macroeconomic shocks.

In particular, we start from the events already identified by Bloom (2009) through the peaks in the VXO. ${ }^{5}$ We then extend the list using natural disaster databases and other publicly available data on armed conflicts, terrorist attacks as well as political elections and judicial decisions. Since the instrument does not need to take values at every period, it is safer to use a small selection of reliable events, rather than a larger array of events that potentially pollutes the information captured in the proxy. We hence exclude from the list all the events that may have been anticipated by economic

\footnotetext{
${ }^{5}$ It may be noted that those peaks do not necessarily indicate an exogenous variation in uncertainty, but potentially an endogenous response to other macroeconomic shocks, or even uncertainty shocks that may have occurred earlier in the sample. Indeed, investigating the timing of the dummies, we found that the peaks of the VXO quite regularly occur with a few months delay after the events used by Bloom (2009) to interpret them. For example, the peak of the VXO in March 1980 is usually interpreted as the effect of the crisis related to the US hostages in Iran and to the Soviet invasion of Afghanistan, events that took place in November and December 1979, respectively; Black Monday occurred in October 1987, while the VXO peaked in November 1987; Iraq invaded Kuwait in August 1990, while the VXO peaked in October 1990; Worldcom bankruptcy happened in July 1990, while the VXO peaked in September 1990. While the peaks of the VXO might be associated to other, contemporaneous exogenous variations in uncertainty, the unclear correspondence of the VXO peaks and the underlying events raises the risk that the proxy based on dummies on the VXO mismatches the timing of the reduced form shocks of the VAR. For this reason, we prefer to inform our dummies using the price of safe haven assets, rather than a dummy variable in correspondence to the peaks of the VXO, as proposed by Carriero et al. (2015). The peaks of the VXO are used only to identify underlying events, whose exact timing is then assessed separately.
} 
agents and that are potentially related to other relevant macroeconomic shocks. The baseline specification of the analysis consists of 38 events. ${ }^{6}$ Table D.5 in the appendix lists all the 38 events, while the database available on-line lists all the events. ${ }^{7}$ In Section 5.5 we show that the results are robust to using all events in the construction of the proxy variable.

To assess when the news about the events hit the market, we rely on the news releases from the Bloomberg News agency. We do so because Bloomberg News releases are a main source of information for market participants, and they aggregate information from several sources around the world, hence giving us access to a broad set of information. For the 38 events used in the baseline specification, whenever Bloomberg News could not be used to assess when the news hit the market for a specific event, either because the News agency was not fully operational yet, or because it not clear which release was the relevant one, other reliable sources were used. ${ }^{8}$ Of the 38 events, 19 were based upon Bloomberg News, the remaining 19 using alternative sources.

\subsection{Comparing candidate safe haven assets}

We consider different assets as candidate safe haven assets to construct our proxy. In this preliminary assessment, we use daily data on the price of precious metals (gold, silver, platinum) and government bonds (US treasury bonds with 3 month and 30 year maturity). We also consider the first principal component computed on the price of the precious metals, the daily measure of the VXO, and a dummy variable taking value \pm 1 when the event was judged to imply an increase or a decrease in uncertainty, and 0

\footnotetext{
${ }^{6}$ The use of 38 events for the identification of the VAR model estimated on about 400 monthly observations is consistent with the number of shocks per observations in the sample of Mertens and Ravn (2013), who use 13 to 16 events for 228 quarterly observations.

${ }^{7}$ The list is available on https://sites.google.com/site/michelepiffereconomics/home/research-1.

${ }^{8}$ For example, Bloomberg News agency releases do not cover the period in which the Berlin Wall fell, November 9, 1989. Nevertheless, it is uncontroversial that the trigger of the event was the reply given by the GDR official Günter Schabowski at the press conference in that day, which was broadcast at 7:17 PM, Berlin time, following which East Germans rushed to boarder crossing. As such, the news can be comfortably classified as having occurred before the markets opened the following day.
} 
when the variation in uncertainty could not be a priori assessed. This improves upon a dummy variable taking value 1 for all events, which would not distinguish between increases and decreases in uncertainty. The use of daily data in this preliminary analysis ensures a level playing field in the comparison of the candidate assets, as it is the highest frequency available for all candidates.

For each of the candidate safe haven asset, we compute the percentage variation of the corresponding price before and after the occurrence of each of the event. We then aggregate these variations into a monthly time series summing up within a month, as in Romer and Romer (2004). This yields eight candidate proxies for uncertainty shocks. While in principle the identification of structural VARs can be done with several instruments for the same structural shock, it is appropriate to assess which candidate instruments are more suitable for the analysis.

We use two criteria to assess which asset is most suitable for the construction of the proxy. Firstly, the candidate proxy should Granger-cause the majority of measures of uncertainty available from the literature (we use the measures by Jurado et al. (2015), Bachmann et al. (2013), the VIX, the VXO and a measure of realized volatility of the S\&P 500). Rejecting the null hypothesis of no Granger-causality suggests that the candidate proxy indeed reflects variations in uncertainty. Secondly, we require the instrument to be sufficiently strong, i.e. to correlate significantly with the the VAR residuals corresponding to the uncertainty measure as dependent variable. In particular, we require that the $F$ statistic for the significance of $\beta$ in the VAR equation of the measure of uncertainty higher than 10 (Stock and Yogo, 2005). In the baseline specification of the model we use the VXO as a measure of uncertainty.

The results of the tests are shown in Table 1. Bold values report values supporting the candidate proxy. The Granger-causality tests are displayed in the top part of the table. The results of the tests on the strength of the candidate instruments are shown in the lower part of Table 1. For the former, we report the p-value on the Grangercausality from the candidate proxy variable to the different measures of uncertainty. 
For the latter, we report the $F$ statistic on the significance of the candidate proxy, which enters as the regressor in the equation featuring as a dependent variable the residual on the VXO. Overall, the tests strongly support the price of gold as a measure to inform the proxy of uncertainty shock. While also proxies based on other assets such as platinum and the US treasury bills somewhat pass the Granger-causality tests, they do not pass the test on the strength of the instrument. Therefore, the remainder of the analysis proceeds using the proxy informed by the price of gold. ${ }^{9}$

Table 1: Preliminary tests on candidate assets for the construction of the proxy

\begin{tabular}{|c|c|c|c|c|c|c|c|c|}
\hline & Gold & Silver & Platinum & $\mathrm{PC}$ & 3mTBILL & 30yBond & VXO & Dummy \\
\hline & \multicolumn{3}{|c|}{ Granger-causality from } & \multicolumn{2}{|c|}{$\begin{array}{c}\text { candidate proxy } \\
\text { (p-values) }\end{array}$} & to measure & \multicolumn{2}{|c|}{ of uncertainty } \\
\hline Jurado et al. (2015) & 0.00 & 0.00 & 0.75 & 0.74 & 0.21 & 0.4 & 0.86 & 0.75 \\
\hline Bachmann et al. (2013) & 0.75 & 0.94 & 0.04 & 0.69 & 0.31 & 0.82 & 0.72 & 0.09 \\
\hline VIX & 0.00 & 0.61 & 0.00 & 0.96 & 0.00 & 0.02 & 0.01 & 0.26 \\
\hline $\mathrm{VXO}$ & 0.00 & 0.35 & 0.00 & 0.39 & 0.01 & 0.01 & 0.19 & 0.4 \\
\hline Realized Volatility & 0.00 & 0.93 & 0.00 & 0.98 & 0.00 & 0.00 & 0.00 & 0.91 \\
\hline \multicolumn{9}{|c|}{$\begin{array}{l}\text { Strength of the candidate instrument } \\
\text { (F-statistic) }\end{array}$} \\
\hline Residual in VXO eq. & 11.90 & 4.50 & 2.29 & 0.00 & 1.90 & 0.05 & 4.99 & 5.28 \\
\hline
\end{tabular}

The availability of intradaily data for the price of gold allows us to construct even narrower windows around the events, improving on the identification of the uncertainty shocks. In particular, we use data on physical gold from the London Bullion Market. This market is an over-the-counter market, but it organizes two auctions every day, at 10:30 and at 15:00, and the price of these auctions is publically available. More detail

\footnotetext{
${ }^{9}$ Baur and McDermott (2010) and Baur and Lucey (2010) find empirical support for the hypothesis that gold is a safe haven asset. Anecdotal evidence from the media also points towards gold as potentially reflecting uncertainty shocks. For example, after the terrorist attack in Paris, November 16, 2015, the Wall Street Journal titled an article "Gold Prices Rise as Paris Attacks Spark SafeHaven Demand", and the CNBC titled a TV discussion "Safe haven assets gain after Paris attacks". Overall, we found that newspapers tend to comment on the price of gold and other safe haven assets after several events that we use.
} 
on the gold price data is available in Section A in the appendix. In Section 5 we show that the strength of the instrument increases when moving from daily to intradaily data, as the relevant $F$ statistic increases from 11.90 to 19.38 .

\subsection{The proxy}

Figure 1: Proxy for uncertainty shocks: variations in the price of gold around events

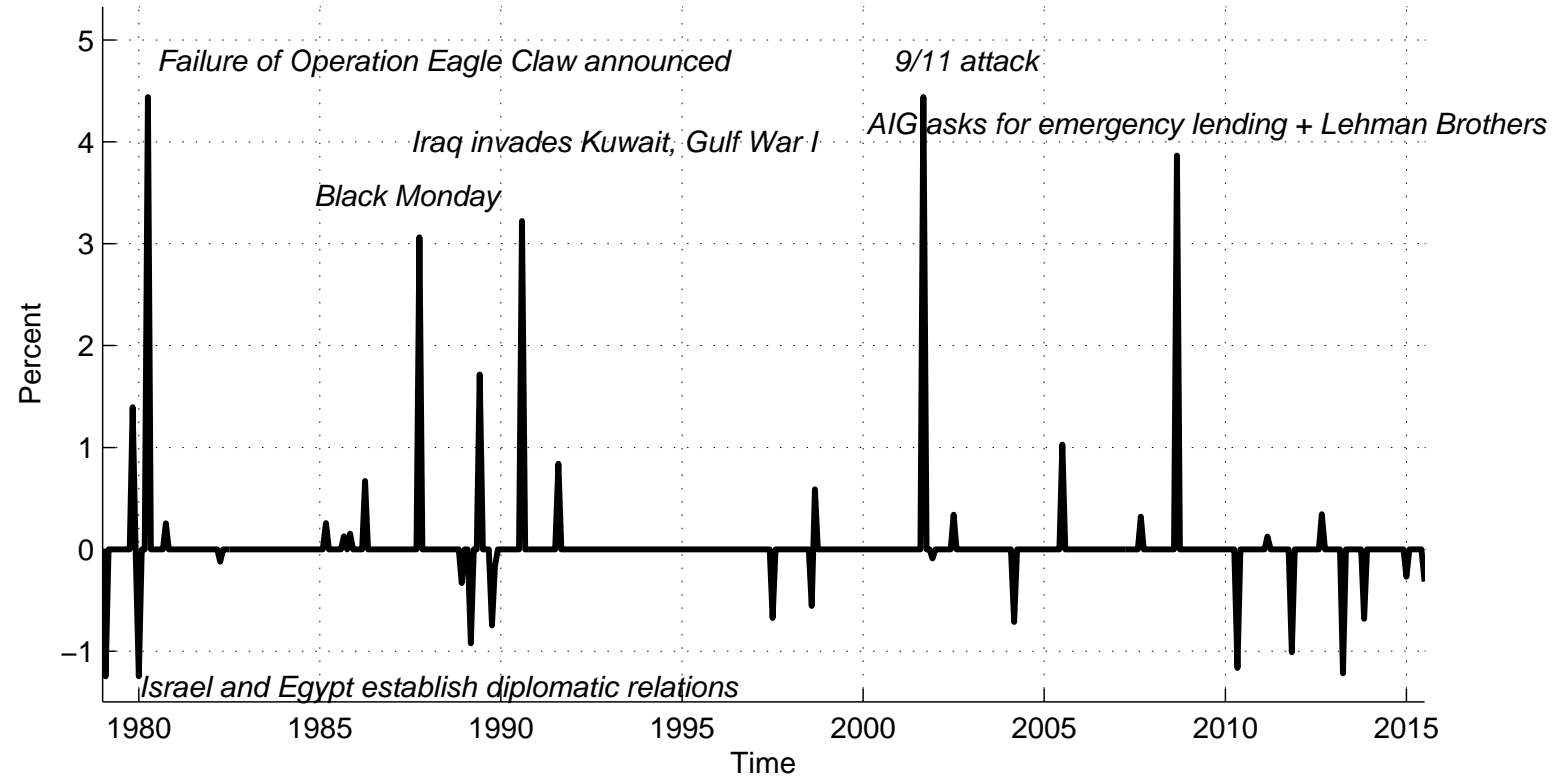

The final proxy for uncertainty shocks is shown in Figure $1 .^{10}$ The realizations are well distributed among the sample. The peaks of the proxy tend to be predominantly positive and of higher magnitude when positive, a feature consistent with the literature on uncertainty shocks (Bloom, 2014). The peaks are intuitive with respect to the nature of the underlying event, as indicated by the labels in Figure 1. Figure D.5 in the appendix shows the histogram for the variations of the price of gold along the events, while Section B in the appendix discusses a number of illustrative events in greater detail in order to provide further intuition behind the proxy. We refer to a positive uncertainty shock as a shock that exogenously increases uncertainty, and

\footnotetext{
${ }^{10}$ To avoid the results from being driven by outliers, the proxy has been winsorized at the one percent level, although this does not affect the results. Winsorization eliminates outliers in the distribution by replacing values in the tails with those of the respective percentiles.
} 
which is hence associated with an increase in the proxy for the uncertainty shock.

Before using the computed instrument in the identification of the VAR, we further assess the relevance and exogeneity conditions discussed in Section 2, equations (2) and (3) respectively. While these conditions are not directly testable, an indirect assessment can be established using estimates of several structural shocks available in the literature. To do so, we deploy the large set of external instruments used in Stock and Watson (2012) to identify oil, monetary policy, productivity, financial and fiscal policy shocks, as well as two external instruments for uncertainty shocks that they derive. These are the residual of a univariate autoregression with two lags on the VIX, and the common component of the different countries' policy uncertainty indexes from Baker and Bloom (2013). We consider the regression $m_{t}=\alpha+\beta x_{t}+\epsilon_{t}$, where $m_{t}$ is our proxy for uncertainty shocks and $x_{t}$ is each of the external instruments listed in Table 2, one at a time. For each regression, we assess the statistical significance of $\beta$ based on white heteroscedasticity-consistent standard errors.

Table 2: Relationship between our proxy of uncertainty shocks and the instruments used in Stock and Watson (2012) for several structural shocks

\begin{tabular}{|c|c|c|c|c|c|c|}
\hline Shock & Source & $\beta$ & S.E. & P-value & Obs & Sample \\
\hline \multirow{3}{*}{ Oil } & Kilian (2008) & -0.336 & 0.323 & 0.3 & 309 & $1979 \mathrm{M} 01$ to $2004 \mathrm{M} 09$ \\
\hline & Ramey and Vine (2010) & 0.918 & 1.355 & 0.5 & 397 & $1979 \mathrm{M} 01$ to $2012 \mathrm{M} 01$ \\
\hline & Hamilton (2003) & 0.106 & 0.119 & 0.37 & 393 & $1979 \mathrm{M} 01$ to $2011 \mathrm{M} 09$ \\
\hline \multirow{3}{*}{ Monetary Policy } & Romer and Romer (2004) & -3.810 & 2.822 & 0.18 & 216 & 1979M01 to $1996 \mathrm{M} 12$ \\
\hline & Smets and Wouters (2007) & 0.232 & 0.144 & 0.11 & 104 & 1979Q1 to 2004Q4 \\
\hline & Sims and Zha (2006) & -0.052 & 0.040 & 0.2 & 291 & $1979 \mathrm{M} 01$ to $2003 \mathrm{M} 03$ \\
\hline \multirow{2}{*}{ Productivity } & Basu et al. $(2006)^{11}$ & -0.103 & 0.113 & 0.36 & 132 & 1979Q1 to 2011Q4 \\
\hline & Smets and Wouters (2007) & 0.268 & 0.191 & 0.16 & 104 & 1979Q1 to $2004 \mathrm{Q} 4$ \\
\hline \multirow{3}{*}{ Financial } & TED spread & 0.903 & 0.628 & 0.15 & 394 & 1979M01 to $2011 \mathrm{M} 10$ \\
\hline & Gilchrist and Zakrajšek (2012) & 0.583 & 0.554 & 0.29 & 127 & 1979Q1 to 2010Q3 \\
\hline & Bassett et al. (2014) & 0.597 & 0.392 & 0.13 & 76 & 1992Q1 to $2010 \mathrm{Q} 4$ \\
\hline \multirow{3}{*}{ Fiscal Policy } & Ramey (2011) & 5.638 & 20.207 & 0.78 & 128 & 1979Q1 to $2010 \mathrm{Q} 4$ \\
\hline & Fisher and Peters (2010) & 0.400 & 4.362 & 0.93 & 120 & 1979Q1 to $2008 \mathrm{Q} 4$ \\
\hline & Romer and Romer (2010) & 0.820 & 0.604 & 0.18 & 116 & 1979Q1 to 2007Q4 \\
\hline \multirow{2}{*}{ Uncertainty } & $\mathrm{AR}(2)$ resid. of VIX & 0.302 & 0.165 & 0.07 & 394 & 1979M01 to 2011M10 \\
\hline & Baker et al. (2013) & 0.016 & 0.012 & 0.18 & 325 & $1985 \mathrm{M} 01$ to $2012 \mathrm{M} 01$ \\
\hline
\end{tabular}

Notes: Reported standard errors are white heteroscedasticity-consistent standard errors. If the external instrument, $x_{t}$, is only available on quarterly frequency, our uncertainty instrument, $m_{t}$, is aggregated by averaging across months. 
The results of these test, summarized in Table 2, confirm that our instrument for uncertainty shocks is not accidentally picking up other structural shocks, although the monetary policy shock taken from Smets and Wouters (2007) and the financial shock from Bassett et al. (2014) are not far from being borderline cases. Reassuringly, the only significant correlation is found with one of the two uncertainty shock instruments, namely the residual from an $\mathrm{AR}(2)$ regression on the VIX, while the common component of the the policy uncertainty indexes across countries is not found to be significantly related to our instrument. Overall, we conclude that the evidence supports our assumptions of relevance and exogeneity of the instrument.

\section{Data and specification}

Following the construction of the proxy for uncertainty shocks, we deploy it for the identification of uncertainty shocks from a VAR model. To facilitate comparison with the recursive identification used in Bloom (2009), we use a specification of the VAR model very similar to his one.

We consider a vector of eight endogenous variables that enter the VAR model in the following order:

$$
\boldsymbol{y}_{t}=\left(\begin{array}{c}
\Delta \log \left({\left.\mathrm{S} \& \mathrm{P} 500_{t}\right)}_{\mathrm{VXO}_{t}}\right. \\
\text { federal funds rate } \\
\Delta \log \left(\text { wages }_{t}\right) \\
\Delta \log \left(\mathrm{CPI}_{t}\right) \\
\operatorname{hours}_{t} \\
\Delta \log \left(\text { employment }_{t}\right) \\
\Delta \log \left(\text { industrial production }_{t}\right)
\end{array}\right) .
$$

In the baseline specification, variables either enter in levels or in log differences in order to ensure the stationarity of the system. Based on information criteria we estimate a 
reduced form VAR with five lags, considering alternative lag lengths in the robustness section. The sample spans from 1962M8 to 2015M6. The data included in the VAR model is plotted in Figure D.6 in the appendix.

Our specification of the model deviates from Bloom (2009) in three ways. Firstly, we update the sample up to 2015M6 in order to include more recent uncertainty related events in our database. Secondly, we let the variables enter in log differences rather than in deviations from HP trends (Hodrick and Prescott, 1997), since such a detrending might distort the dynamics in the underlying time series. ${ }^{12}$ Thirdly, we use the entire dynamics of the VXO as a measure of uncertainty instead of a dummy series that takes the value of unity in correspondence to the peaks of the series. For robustness, we will also consider specifications in levels and on HP detrended data.

The actual identification of the model, i.e. the estimation of $\boldsymbol{b}^{u}$ given the instrument and the estimates of the reduced form VAR, is discussed in detail in Section C in the appendix.

\section{$5 \quad$ Results}

This section discusses the results of the analysis across four dimensions: tests on the strength of the proxy, estimated structural shocks, impulse responses and forecast error variance decompositions. We compare the results of the proxy SVAR with the recursively identified SVAR. In short, we find that the proxy strongly relates to VXO, employment and industrial production, and that the proxy SVAR exhibits a stronger effect of uncertainty shocks on the real economy both in terms of impulse responses and of variance decompositions. In addition, monetary policy responds more aggressively to an uncertainty shock.

\footnotetext{
${ }^{12}$ See King and Rebelo (1993), Harvey and Jaeger (1993), Guay and St-Amant (2005) and Meyer and Winker (2005) for a discussion of potential distortionary effects induced by using of HP filtered data. Indeed, Jurado et al. (2015) find that the overshooting in response to an uncertainty shock documented in Bloom (2009) is an artifact of the transformation of the variables.
} 


\subsection{Tests on the strength of the instrument}

Table 3: Tests on the strength of the instrument

\begin{tabular}{lcccccccc}
\hline & \multicolumn{7}{c}{ Reduced form shocks on: } \\
\cline { 2 - 4 } & $\begin{array}{c}\text { VXO } \\
\text { (log dif.) }\end{array}$ & $\begin{array}{c}\text { Fed funds } \\
\text { (level) }\end{array}$ & $\begin{array}{c}\text { Wage } \\
\text { rate (level) }\end{array}$ & $\begin{array}{c}\text { CPI } \\
\text { (log dif.) }\end{array}$ & $\begin{array}{c}\text { Hours } \\
\text { (log dif.) }\end{array}$ & $\begin{array}{c}\text { Employment } \\
\text { (log dif.) }\end{array}$ & $\begin{array}{c}\text { Industrial } \\
\text { production } \\
\text { (log dif.) }\end{array}$ \\
$\beta$ & $-0.80^{* *}$ & $166.4012^{* * *}$ & -5.582 & -0.026 & 0.020 & $-4.133^{*}$ & $-0.066^{* * *}$ & $-0.182^{* * *}$ \\
$\mathrm{~T}$ & 438 & 438 & 438 & 438 & 438 & 438 & 438 & 438 \\
$\mathrm{~F}$ & 4.336 & 19.380 & 1.324 & 1.076 & 0.779 & 3.654 & 9.224 & 8.035 \\
$\mathrm{R}^{2}$ & 0.098 & 0.042 & 0.003 & 0.002 & 0.002 & 0.008 & 0.020 & 0.018 \\
& & & & & & & &
\end{tabular}

Notes: The models estimated are of the form $\hat{u}_{i, t}=\alpha+\beta_{i} m_{t}+\eta_{i, t}$ with $\hat{u}_{i, t}$ the residual in the equation of the VAR corresponding to the variable indicated in each column of the table and $m_{t}$ the proxy variable explained in Section 3. The null hypothesis refers to $\beta_{i}=0$. The statistical significance of $\hat{\beta}_{i}$ indicated in the table is constructed using the asymptotic distribution of the OLS estimator. The bootstrapped distribution delivered an even stronger statistical significance of the parameters $\beta_{i}$, with the parameter in the first, third and sixth column being significant at a $1 \%$ confidence level (unreported).

Starting from equations (4), we test the significance of the $\beta$ parameters $\left(\beta_{i}, i=\right.$ $1,2, \ldots, K)$. The results of the validity tests are reported in Table 3. They suggest that the instrument contains relevant information for the reduced form residuals and thus for the variables included in the system. The VXO is the only measure positively related to the proxy for uncertainty shocks in a statistically significant way, while four other variables - the stock market index, hours worked, employment and industrial production - are negatively related and in a statistically significant way. The reduced form residuals associated with the federal funds rate, wages and the consumer prices are found to be statistically unrelated to the instrument. The $F$ statistic on the null hypothesis $\beta_{i}=0$ is above 10 for the residual on the VXO equation, with an $F$ statistic even higher than the one found using the proxy based on daily data (Section 3). The $F$ statistic is close to 10 for the residual on the equations of the employment and of industrial production. Note also that the $F$ statistics are much higher for the residuals in the equation of $\mathrm{VXO}$ than in the equation of the stock market index, confirming again that the proxy is picking up uncertainty shocks rather than financial shocks. 
Given that the majority of the measures respond significantly to the proxy and that the signs of those responses are in line with expectations, we conclude that the proxy is a valid instrument in the chosen setup.

\subsection{Estimated uncertainty shocks}

Figure 2 reports the estimated shocks from both the recursively identified SVAR and the proxy SVAR.

The top panel plots the proxy variable constructed in Section 3 jointly with the uncertainty shock uncovered from the proxy SVAR. The correlation between the proxy for the uncertainty shocks and the uncertainty shocks equals about 25 percent. The two series share several peaks, including most notably, Black Monday, the 9/11 attack and the collapse of Lehman Brothers. The structural shocks obtained from the proxy SVAR also include a number of events that we have not incorporated in the construction of the proxy variable, as for example the US downgrading. We did not include this event in the proxy variable, because within the same window (which goes from Friday to Monday) the European Central Bank reactivated SMP, and we could not control for this monetary event. The estimated uncertainty shocks attribute a strongly positive peak to that period.

The lower panel compares the two structural shock series obtained from the recursively identified SVAR and the proxy SVAR. Both series of structural uncertainty shocks exhibit higher volatility in the aftermath of the early 1980s recession, after the burst of the dotcom bubble in the early 2000s an during the recent financial crisis. Their correlation of about 84 percent indicates that the identifications are not diametrically opposed to each other. However, the shock series from the proxy SVAR seems somewhat smoother and generally exhibits smaller peaks. 
Figure 2: Estimated shocks and proxy of uncertainty shocks
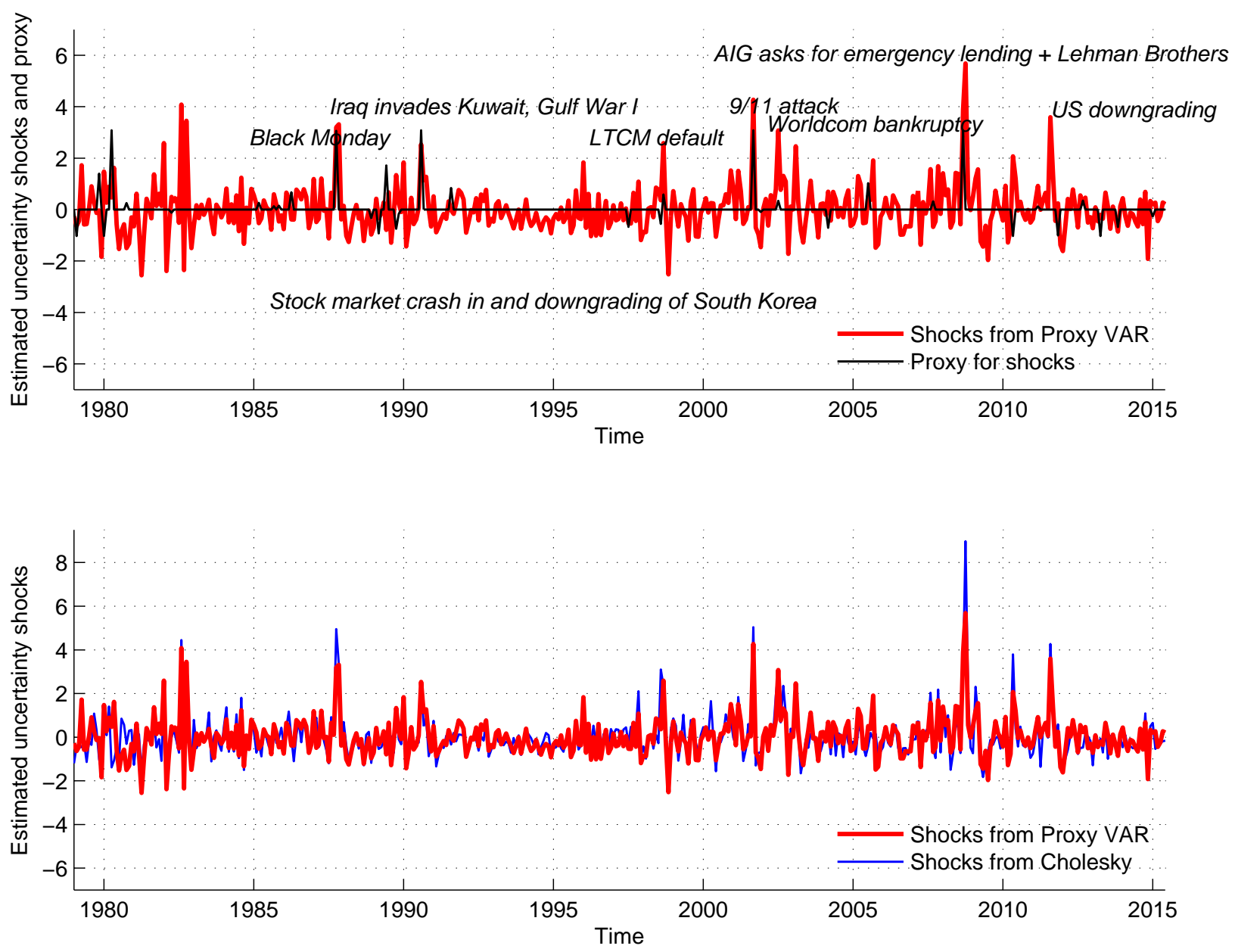

\subsection{Impulse Responses}

In order to facilitate comparison among the impulse responses from two different identification approaches, we first compute the impulse responses in the proxy VAR as the response to a one standard deviation shock. We then give an impulse to the recursively identified model such that the VXO increases on impact by just as much as in the case of the proxy VAR. Figure 3 plots the responses to an uncertainty shock. We first discuss those responses stemming from the proxy VAR in isolation, before turning to the comparison. Error bands are computed using a Wild bootstrap. ${ }^{13}$

\footnotetext{
${ }^{13}$ To compute the distribution, we follow Mertens and Ravn (2013) and Gertler and Karadi (2014) in using the wild bootstrap developed by Gonçalves and Kilian (2004). The wild bootstrap resamples
} 
Figure 3: Impulse responses to an uncertainty shock
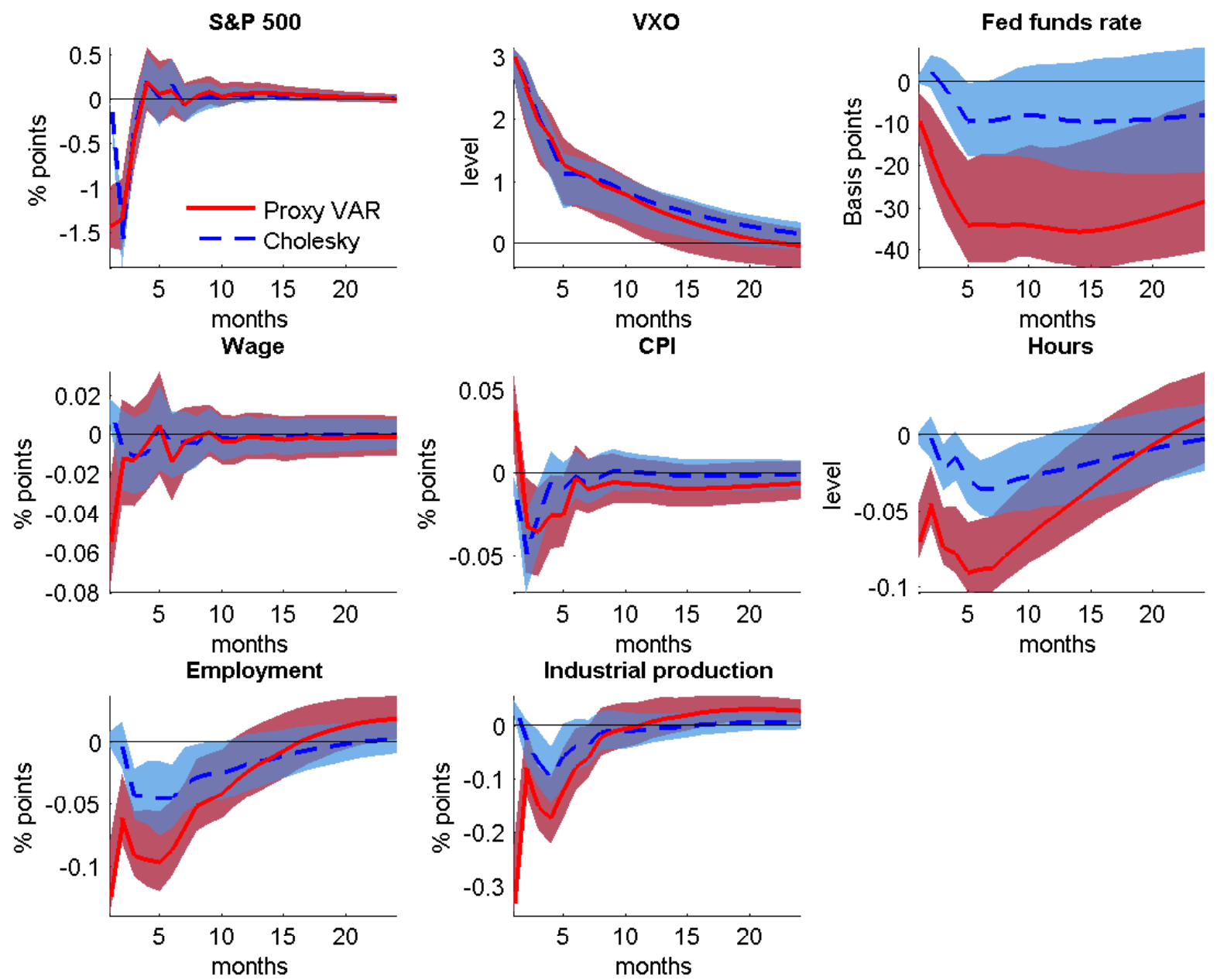

Note: pointwise 90 percent confidence bands reported based on 1000 bootstrap replications.

An uncertainty shock identified within the proxy SVAR approach affects financial

the data by changing the sign of the estimated vectors of reduced form shocks at randomly-selected periods, and by changing the sign of the instruments in correspondence to the same periods. More precisely, generate a vector $\boldsymbol{c}$, of the same length of the reduced form shocks, which at every period $t$ takes value +1 or -1 with equal probability. Then, compute $\boldsymbol{r}_{t}^{\text {pseudo }}=c_{t} \cdot \boldsymbol{r}_{t}$, i.e. pseudo reduced form shocks that differ from the original ones not by the order but only by the sign, as specified by the random vector $\boldsymbol{c}$. Use these pseudo reduced form shocks and the estimates of the VAR to recursively generate pseudo data $\boldsymbol{y}_{t}^{\text {pseudo }}$. Estimate the VAR using $\boldsymbol{y}_{t}^{\text {pseudo }}$. Identify the model using instruments $m_{t}^{\text {pseudo }}=c_{t} \cdot m_{t}$, i.e. using a pseudo measure of the proxy that differs from the original proxy only for the sign specified by the same vector $\boldsymbol{c}$. Brüggemann et al. (2016) propose using a residual block bootstrap, arguing that the fourth moments are not properly bootstrapped in a wild bootstrapping approach. Given that the distortions for the point wise confidence bands are minor, we follow the literature and deploy a wild bootstrapping to obtain confidence bands. 
markets, monetary policy and the real economy, but has a very limited impact on nominal variables. The stock market index falls on impact, consistent with Caldara et al. (2014), accompanied by a drop in employment, industrial production and hours worked. While the recovery of the financial markets is rather rapid, it takes the real economy two to three quarters to return to pre-shock levels. This recovery is supported by a loose monetary policy coming into play with some lag after the shock. Although wages and prices do not react significantly, the impulse responses seem to reflect pressure on the two variables, generally regarded as downward rigid. Given that wages do not react, additional adjustment on the labor market is borne by hours worked that remain low for about three quarters. Note that the real variables and the stock market index enter in growth rates, and hence their levels still justify a monetary expansion even after their growth rates have reversed, as indeed we find when considering the response of the federal funds rate.

There are three main differences between the responses in the recursively identified VAR and the proxy SVAR. Firstly, in the proxy SVAR the stock market reacts instantaneously to an uncertainty shock, potentially opening up a channel for a stronger transmission of the shock to the real economy. Secondly, employment, industrial production and hours react faster and significantly more negatively when identified based on the proxy SVAR. Thirdly, the proxy SVAR exhibits an overshooting in real variables, as predicted by the theoretical model in Bloom (2009). This does not occur with the recursive uncertainty shock. In addition, it should be noted that prices react negatively in the recursive identification, while monetary policy responds with a stronger decrease in the federal funds rate in the proxy SVAR, as compared to the recursively identified model. The results are consistent with Carriero et al. (2015), including the impact increase in the consumer price index.

While the robustness of the results is addressed in greater detail in Section 5.5, two remarks are worth noting here. Firstly, the results are very robust to several alternative specifications, including alternative specifications of the reduced form VAR 
and alternative computations of the proxy measure. Secondly, the results cannot be generated by simply using an alternative recursive order, placing the measure of uncertainty first. In this latter case, in fact, the response of employment and industrial production would still be estimated to be significantly smaller than in the case of the proxy SVAR.

\subsection{Forecast error variance decomposition}

Table 4: Forecast Error Variance Decomposition

\begin{tabular}{|c|c|c|c|c|c|c|c|c|}
\hline hor. & $\begin{array}{l}\text { S\&P } 500 \\
\text { (log dif.) }\end{array}$ & $\begin{array}{l}\text { VXO } \\
\text { (level) }\end{array}$ & $\begin{array}{l}\text { Fed funds } \\
\text { rate (level) }\end{array}$ & $\begin{array}{c}\text { Wage } \\
\text { (log dif.) }\end{array}$ & $\begin{array}{c}\text { CPI } \\
\text { (log dif.) }\end{array}$ & $\begin{array}{l}\text { Hours } \\
\text { (levels) }\end{array}$ & $\begin{array}{c}\text { Employment } \\
\text { (log dif.) }\end{array}$ & $\begin{array}{c}\text { Industrial } \\
\text { production } \\
\text { (log dif.) }\end{array}$ \\
\hline \multicolumn{9}{|c|}{ from proxy $S V A R$} \\
\hline 1 & 0.20 & 0.45 & 0.05 & 0.00 & 0.00 & 0.13 & 0.31 & 0.40 \\
\hline 6 & 0.21 & 0.45 & 0.25 & 0.01 & 0.06 & 0.41 & 0.50 & 0.45 \\
\hline 12 & 0.21 & 0.42 & 0.37 & 0.01 & 0.06 & 0.47 & 0.50 & 0.43 \\
\hline 24 & 0.21 & 0.39 & 0.45 & 0.01 & 0.07 & 0.36 & 0.48 & 0.43 \\
\hline \multicolumn{9}{|c|}{ from recursive $S V A R$} \\
\hline 1 & 0.00 & 0.90 & 0.00 & 0.00 & 0.00 & 0.00 & 0.00 & 0.00 \\
\hline 6 & 0.20 & 0.90 & 0.01 & 0.01 & 0.06 & 0.04 & 0.07 & 0.05 \\
\hline 12 & 0.20 & 0.87 & 0.02 & 0.01 & 0.06 & 0.06 & 0.09 & 0.05 \\
\hline 24 & 0.20 & 0.83 & 0.03 & 0.01 & 0.05 & 0.05 & 0.09 & 0.05 \\
\hline
\end{tabular}

The forecast error variance decompositions are reported in Table 4. While the recursive and the proxy SVAR identifications isolate uncertainty shocks that explain similar fractions of nominal and financial variables, at least at longer horizons, the real variables - employment, industrial production and hours worked - are strongly affected by the proxy SVAR uncertainty shock. In contrast, the fraction explained by the recursively identified shock is very small.

It should also be noted that only a small fraction of the variation in the federal funds rate at short horizons is explained by uncertainty shocks. This fraction grows for larger horizons, potentially reflecting the reaction of the monetary authority to the 
depressed real economy. We take the small fraction of the short horizon as reassuring, in that we do not pick up a monetary policy shock with the instrumental identification.

A feature of the recursively identified uncertainty shock is that it explains close to all of the variation in the uncertainty measure used in the model. However, the VXO not only contains information about uncertainty but also about the risk aversion of market participants (Bekaert et al., 2013; Ludvigson et al., 2015) and, hence, it should be considered surprising that an uncertainty shock is capable of explaining nearly the entire variation in this measure. As opposed to that, the variation in the VXO explained by the proxy SVAR uncertainty shock fluctuates around 50 percent.

\subsection{Robustness}

We assess the sensitivity of the results along a number of dimensions. Specifically, we vary the lag length of the model, employ levels, HP filter the variables in the VAR as done in Bloom (2009), use the uncertainty measures from Jurado et al. (2015) and from Bachmann et al. (2013) as alternatives for the VXO in the baseline, consider an alternative proxy based on all events in the database (see Section 3), aggregate the daily proxy into a monthly time series using the aggregation by Gertler and Karadi $(2014)^{14}$ and change the ordering of the variables in the recursive identification. Overall the results are very robust to all these variations to the setup.

Figures D.7 to D.15 in the appendix report the set of impulse responses for a range of specifications along the dimensions mentioned above. The main findings from the baseline specifications are insensitive to the changes considered. In response to an uncertainty shock, the stock market index drops instantaneously, the real economy contracts significantly stronger with an overshooting in subsequent periods, while monetary policy reacts more aggressively in the proxy SVAR as compared to the recursive setup.

We also vary the ordering in the recursive model and let the financial variable en-

\footnotetext{
${ }^{14}$ Their aggregation accounts for the timing of the event within the month.
} 
ter as the first variable (Figure D.14 in the appendix). While the reordering renders the response of the financial variable negative on impact, employment and industrial production still decrease significantly less if compared to the proxy SVAR. This may be due to the fact that the recursive approach is identifying an uncertainty shock effectively being a weighted average not only of financial and uncertainty shocks, but also other shocks capable of affecting the entire system contemporaneously. We conclude that reordering variables within a recursive identification still falls short of generating the effects of uncertainty shocks captured by the identification strategy proposed in this paper, although it goes in that direction.

\section{Conclusion}

In this paper we assess the economic impact of uncertainty shocks identified within a proxy SVAR. We propose a new proxy for exogenous uncertainty shocks by exploiting the variations of the price of gold around selected events. For the construction of the proxy we set up a database of events that may have impacted on economic uncertainty. We then inform our proxy variable about the relevance of the event for economic uncertainty via the variations in the price of gold around those events. Our proxy covers the time period from 1979 to 2015.

In comparing the uncertainty shock identified within the proposed proxy SVAR framework to a recursively identified shock prominently featured in the literature, we find that uncertainty shocks (1) trigger an instantaneous reaction of the financial market, (2) exhibit a larger and more rapid response of the real economy with a subsequent overshooting as predicted by the model in Bloom (2009), and (3) are followed by a significant and prolonged monetary policy response that is not present in the recursively identified setup. In addition, the uncertainty shock identified in the proxy SVAR explains a larger share in the variance of the real variables, while the fraction explained by the recursively identified shock is rather small. 
While the literature has put much effort in refining measures of uncertainty as such, less work has been done on improving the identification of uncertainty shocks within SVAR models. Our identification strategy based on the constructed proxy variable improves upon the widely used recursive approach of identifying uncertainty shocks, because it uses outside intradaily information for the identification and allows the entire economy to react instantaneously to an uncertainty shock. Overall, we find that uncertainty shocks may be an even stronger driving force of business cycles, as compared to the recursive identification. 


\section{References}

Alessandri, P. and H. Mumtaz (2014). Financial regimes and uncertainty shocks. Working Papers 729, Queen Mary, University of London, School of Economics and Finance.

Bachmann, R., S. Elstner, and E. R. Sims (2013). Uncertainty and economic activity: Evidence from business survey data. American Economic Journal: Macroeconomics 5(2), 217-249.

Baker, S. R. and N. Bloom (2013). Does uncertainty reduce growth? using disasters as natural experiments.

Baker, S. R., N. Bloom, and S. J. Davis (2013). Measuring economic policy uncertainty. Unpublished Manuscript, Stanford University.

Bassett, W. F., M. B. Chosak, J. C. Driscoll, and E. Zakrajšek (2014). Changes in bank lending standards and the macroeconomy. Journal of Monetary Economics 62, $23-40$.

Basu, S., J. Fernald, and M. Kimball (2006). Are technology improvements contractionary? American Economic Review 96(5), 1418-48.

Baur, D. G. and B. M. Lucey (2010). Is gold a hedge or a safe haven? An analysis of stocks, bonds and gold. Financial Review 45(2), 217-229.

Baur, D. G. and T. K. McDermott (2010). Is gold a safe haven? International evidence. Journal of Banking $\&$ Finance 34(8), 1886-1898.

Bekaert, G., M. Hoerova, and M. Lo Duca (2013). Risk, uncertainty and monetary policy. Journal of Monetary Economics 60(7), 771-788.

Bloom, N. (2009). The impact of uncertainty shocks. Econometrica $77(3), 623-685$. 
Bloom, N. (2014). Fluctuations in uncertainty. Journal of Economic Perspectives $28(2), 153-175$.

Bloom, N., S. Bond, and J. van Reenen (2007). Uncertainty and investment dynamics. Review of Economic Studies 74, 391-415.

Brüggemann, R., C. Jentsch, and C. Trenkler (2016). Inference in VARs with conditional heteroskedasticity of unknown form. Journal of Econometrics 191(1), 69-85.

Caggiano, G., E. Castelnuovo, and N. Groshenny (2014). Uncertainty shocks and unemployment dynamics in US recessions. Journal of Monetary Economics 67, $78-92$.

Caldara, D., C. Fuentes-Albero, S. Gilchrist, and E. Zakrajsek (2014). The macroeconomic impact of financial and uncertainty shocks. Unpublished Manuscript.

Carriero, A., H. Mumtaz, K. Theodoridis, and A. Theophilopoulou (2015). The impact of uncertainty shocks under measurement error: A proxy SVAR approach. Journal of Money, Credit and Banking 47(6), 1223-1238.

Cesa-Bianchi, A., M. Pesaran, and A. Rebucci (2014). Uncertainty and economic activity: A global perspective. CESifo Working Paper Series (4736).

Dovern, J., U. Fritsche, and J. Slacalek (2012). Disagreement among forecasters in G7 countries. Review of Economics \& Statistics 94(4), 1081-1096.

Fisher, J. D. and R. Peters (2010). Using stock returns to identify government spending shocks. The Economic Journal 120(544), 414-436.

Gertler, M. and P. Karadi (2014). Monetary policy surprises, credit costs and economic activity. American Economic Journal: Macroeconomics 7(1), 44-76.

Gilchrist, S. and E. Zakrajšek (2012). Credit spreads and business cycle fluctuations. American Economic Review 102(4), 1692-1720. 
Gonçalves, S. and L. Kilian (2004). Bootstrapping autoregressions with conditional heteroskedasticity of unknown form. Journal of Econometrics 123(1), 89-120.

Guay, A. and P. St-Amant (2005). Do the Hodrick-Prescott and Baxter-King filters provide a good approximation of business cycles? Annales d'Economie et de Statistique, 133-155.

Gurkaynak, R. S., B. P. Sack, and E. T. Swanson (2005). Do actions speak louder than words? The response of asset prices to monetary policy actions and statements. International Journal of Central Banking 1(1), 55-93.

Hamilton, J. D. (2003). What is an oil shock? Journal of Econometrics 113(2), 363-398.

Harvey, A. C. and A. Jaeger (1993). Detrending, stylized facts and the business cycle. Journal of Applied Econometrics 8, 231-231.

Hodrick, R. J. and E. C. Prescott (1997). Postwar US business cycles: An empirical investigation. Journal of Money, Credit and Banking, 1-16.

Jurado, K., S. C. Ludvigson, and S. Ng (2015). Measuring uncertainty. American Economic Review 105(3), 1177-1216.

Kilian, L. (2008). Exogenous oil supply shocks: how big are they and how much do they matter for the us economy? The Review of Economics and Statistics 90(2), 216-240.

King, R. G. and S. T. Rebelo (1993). Low frequency filtering and real business cycles. Journal of Economic Dynamics and Control 17(1), 207-231.

Kuttner, K. N. (2001). Monetary policy surprises and interest rates: Evidence from the fed funds futures market. Journal of Monetary Economics 47(3), 523-544. 
Leahy, J. V. and T. M. Whited (1996). The effect of uncertainty on investment: Some stylized facts. Journal of Money, Credit and Banking 28(1), 64-83.

Lucey, B., C. Larkin, and F. A. O'Connor (2013). London or New York: Where and when does the gold price originate? Applied Economics Letters 20.

Ludvigson, S. C., S. Ma, and S. Ng (2015). Uncertainty and business cycles: Exogenous impulse or endogenous response? NBER Working Paper (21803).

Mankiw, N. G., R. Reis, and J. Wolfers (2003). Disagreement about inflation expectations. NBER Macroeconomics Annual 18.

Mertens, K. and M. O. Ravn (2013). The dynamic effects of personal and corporate income tax changes in the United States. The American Economic Review 103(4), $1212-1247$.

Meyer, M. and P. Winker (2005). Using HP filtered data for econometric analysis: Some evidence from Monte Carlo simulations. Allgemeines Statistisches Archiv 89(3), 303-320.

O’Connor, F. A., B. M. Lucey, J. A. Batten, and D. G. Baur (2015). The financial economics of gold - a survey. FIRN Research Paper (2628018).

Olea, J. L. M., J. H. Stock, and M. W. Watson (2012). Inference in structural VARs with external instruments.

Orlik, A. and L. Veldkamp (2014). Understanding uncertainty shocks and the role of black swans. Unpublished Manuscript.

Ramey, V. A. (2011). Identifying government spending shocks: it's all in the timing. Quarterly Journal of Economics 126(1), 1-50.

Ramey, V. A. and D. J. Vine (2010). Oil, automobiles, and the US economy: How much have things really changed? NBER Macroeconomics Annual 25, 333-67. 
Romer, C. D. and D. H. Romer (2004). A new measure of monetary shocks: Derivation and implications. American Economic Review 94(4), 1055-84.

Romer, C. D. and D. H. Romer (2010). The macroeconomic effects of tax changes: Estimates based on a new measure of fiscal shocks. American Economic Review 100, $763-801$.

Rossi, B. and T. Sekhposyan (2015). Macroeconomic uncertainty indices based on nowcast and forecast error distributions. American Economic Review 105(5), 650655.

Scotti, C. (2013). Surprise and uncertainty indexes: Real-time aggregation of realactivity macro surprises: Board of Governors of the Federal Reserve System. International Finance Discussion Papers (1093).

Sims, C. A. and T. Zha (2006). Were there regime switches in US monetary policy? The American Economic Review 96(1), 54-81.

Smets, F. and R. Wouters (2007). Shocks and frictions in US business cycles: A Bayesian DSGE approach. American Economic Review 97(3), 586-606.

Stock, J. H. and M. W. Watson (2012). Disentangling the channels of the 2007-2009 recession. Brookings Papers on Economic Activity.

Stock, J. H. and M. Yogo (2005). Testing for weak instruments in linear IV regression. Identification and inference for econometric models: Essays in honor of Thomas Rothenberg. 


\section{A Data on the gold price}

We use data from the London market of physical gold, formally known as the London Bullion Market. London is the main hub for the trade of physical gold, and trading occurs through spot transactions over the counter. We use the London price of physical gold rather than the New York price on futures contracts on gold for two reasons. Firstly, Bloomberg provides intradaily data on the futures market for only the last 18 months, while the data on the London market dates back to the 1970s. Secondly, the London market is larger in terms of trade volume. ${ }^{15}$ A comparison of the prices on the London spot market and on the New York futures market at daily frequency yields a correlation close to unity.

Since transactions on the London Bullion Market are over-the-counter, market participants are not required to disclose the price of their bilateral agreements. Nevertheless, in order to inform market participants about the tightness of the market, the London Bullion Market Association organizes two auctions per day. The price of such auctions is publicly available. This is the price of gold that we use for the analysis. Auctions take place at 10:30 and 15:00, London time. We refer to these prices as the AM and the PM gold price, respectively. Shortly before 10:30 and 15:00, banks with access to the London Bullion Market vaulting facilities post their orders. It then typically takes 30 seconds to assess if a round of orders can be reconciled with a clearing price, and 3 rounds of orders to find an equilibrium price. Transactions are denominated in US dollars and are settled two days after the transaction.

\footnotetext{
${ }^{15}$ Following O'Connor et al. (2015), in 2013 the net transactions in London had a daily turnover of $21 \mathrm{bn}$ US dollars. This equals $60 \%$ and $350 \%$ of the daily turnover on the New York Stock Exchange and on the London Stock Exchange, respectively. These figures underestimate the size of the London Bullion Market, as they only include net transactions. Information on gross transactions is not publicly available due to the confidentiality guaranteed by over-the-counter trading. According to a survey conducted in 2011, gross figures might be between 5 and 10 times higher than net figures (http://www.lbma.org.uk/assets/Loco_London_Liquidity_Surveyrv.pdf). When considering also gross transactions, London is estimated to account for around $90 \%$ of the sum of the global gold spot, futures and options trading volumes. New York, instead, accounts for around 9\%. The other markets (Shanghai, Tokyo, Mumbai, Dubai and Istanbul) account for the remaining $1 \%$ (Lucey et al., 2013).
} 


\section{B A few examples}

Figure B.4: Gold price around four events

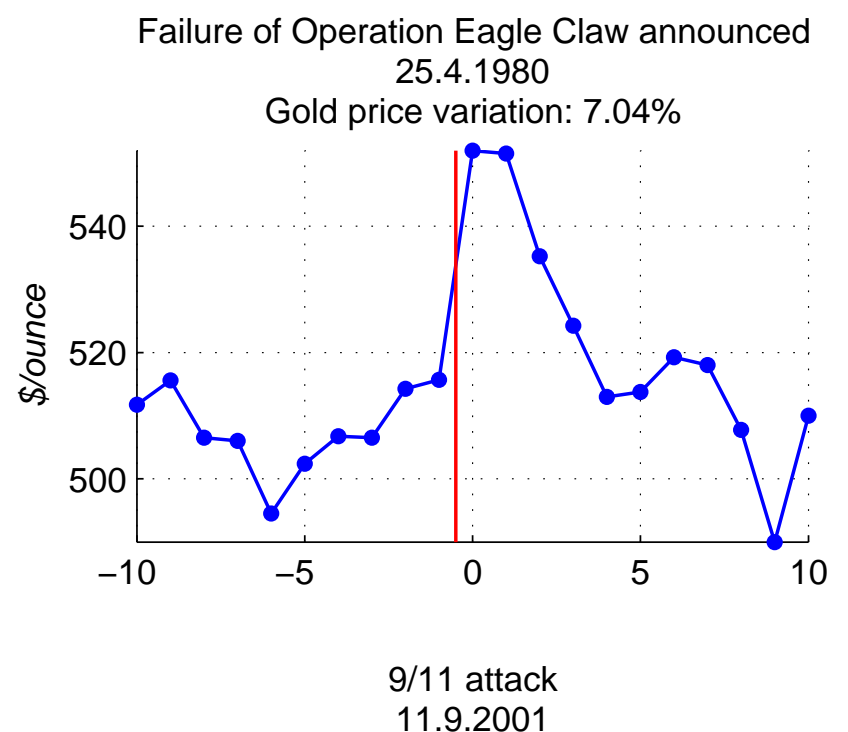
News of Chernobyl disaster arrived to the West 29.4.1986

Gold price variation: $0.67 \%$

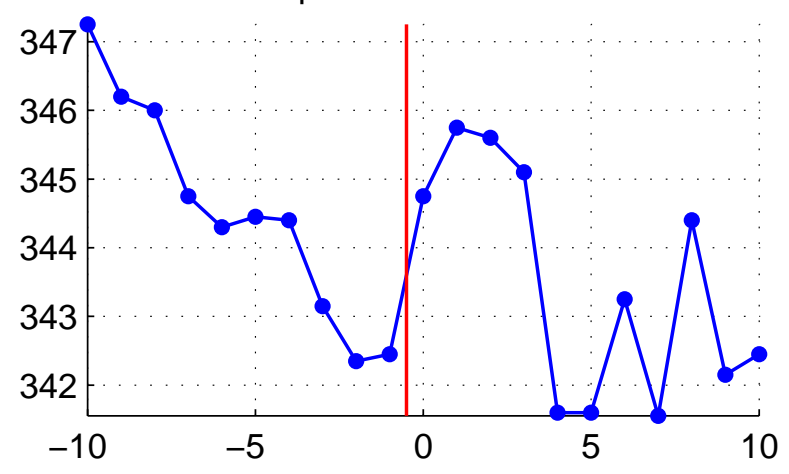

Gold price variation: $5.75 \%$
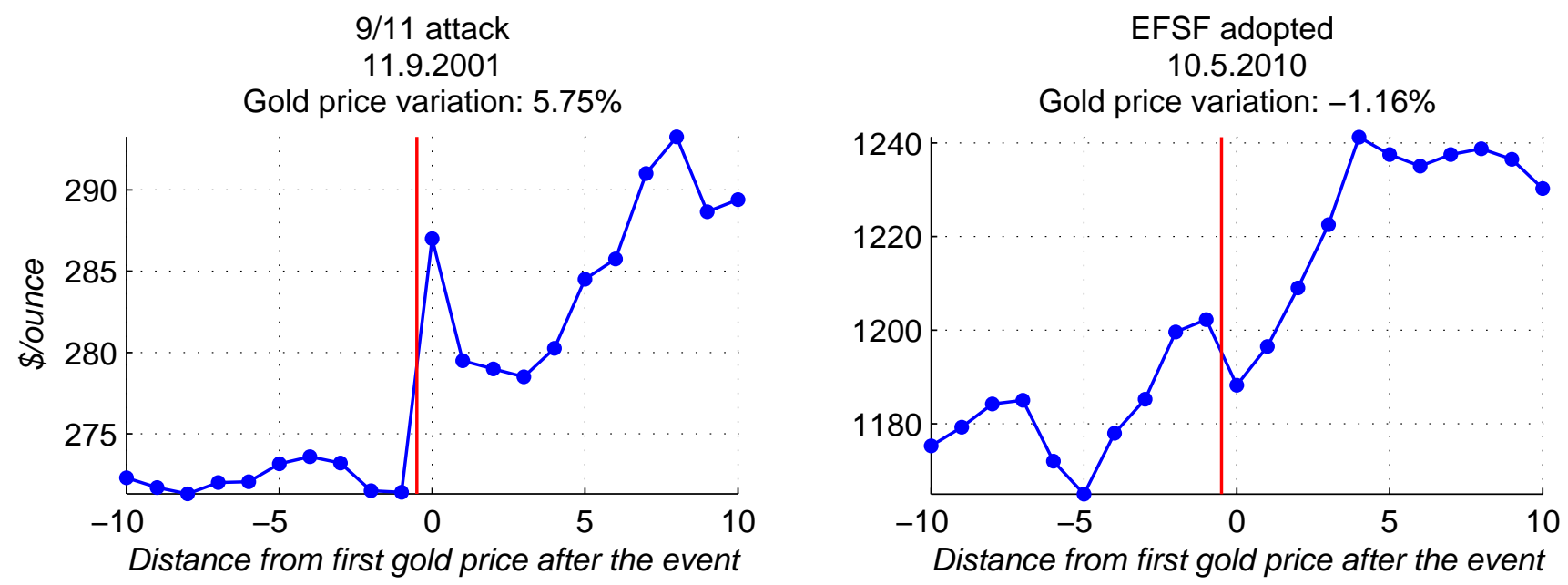

Notes: The figure shows 10 quotes of the price of gold before and 10 quotes of the price of gold after four different events, whose occurrence is indicated by the vertical line. The figures corresponding to all 117 events collected in the analysis is reported in the on-line appendix. The percentage variations are then windsorized at $0.5 \%$ on each side of the tail before agrgegating them into the proxy. This explains the lower values in Figure 1 compared to this figure corresponding to the Failure of Operation Eagle Claw and to the 9/11 attack.

Figure B.4 plots the variation in the intradaily gold price (AM and PM prices) around four selected illustrative events: (1) On 24 October 1980 President Carter authorized a secret military operation to free the hostages in the US embassy in Tehran. 
The operation had been kept secret to anyone outside of the inner circle of the President, and its failure was announced by Carter at 1:00 of the day after, Washington time. The announcement triggered an increase in uncertainty due to the heightened tension in the region, and London priced gold in its AM auction $7.04 \%$ above the PM price of the day before, likely pricing in the increased uncertainty that was soon to unfold between the US and Iran. (2) In the morning of 25 April 1986, technicians at the Chernobyl nuclear station turned off the emergency cooling system and started a test, which was mishandled, resulting in the explosion of the reactor at 01:23 the following morning. The Russian authorities neither informed the neighboring villages nor other countries, the West founding out initially through ordinary tests of radioactivity in Sweden, and then through a US satellite picture of the site. The news of winds coming from East then spread on the day of 29 April, and London priced an increase in the first auction of 30 April, although of only 0.67\%. (3) On September 11, 2001, at 08:46 New York time, 13:46 London time, the first plane of the 9/11 terrorist attack hit the World Trade Center. The event occurred between the AM and the PM London gold auctions. The news of the event traveled around the world immediately and London priced a $5.75 \%$ increase in the price of gold in its PM auction. (4) During the height of the European sovereign debt crisis the European council agreed in an overnight meeting upon the establishment of the European Financial Stabilization Facility (EFSF). The press release communicating the positive outcome of the meeting is dated the night of May 9, 2010, with Bloomberg reporting the news in the early hours of May 10. The price of gold in the morning auction drops $1.2 \%$ as compared to the PM auction the day before.

\section{Identification of the structural VAR}

Given the estimates of the reduced form VAR from Section 2 and the proxy for the uncertainty shock constructed in Section 3, the estimation of the structural VAR 
proceeds as follows (see Mertens and Ravn, 2013, Stock and Watson, 2012 and Olea et al., 2012 for further details).

To estimate impulse responses, run the following regression for each of the $K$ equations of the VAR model:

$$
\hat{u}_{i, t}=\alpha_{i}+\beta_{i} m_{t}+\eta_{i, t}
$$

In this equation, $\hat{u}_{i, t}$ is the estimated VAR residual in equation $i$ and $m_{t}$ is the proxy. It holds that

$$
\hat{\beta}_{i}=\frac{\hat{\operatorname{Cov}}\left(\hat{u}_{i, t}, m_{t}\right)}{\hat{V}\left(m_{t}\right)}=\frac{\hat{E}\left(\hat{u}_{i, t} m_{t}\right)-\hat{E}\left(\hat{u}_{i, t}\right) \hat{E}\left(m_{t}\right)}{\hat{V}\left(m_{t}\right)}=\frac{\hat{E}\left(\hat{u}_{i, t} m_{t}\right)}{\hat{V}\left(m_{t}\right)} \rightarrow \frac{E\left(u_{i, t} m_{t}\right)}{V\left(m_{t}\right)},
$$

where $\hat{C o v}, \hat{V}$ and $\hat{E}$ are the sample covariance, second moment and first moment, respectively, and $\hat{E}\left(u_{i, t}\right)=0$ holds by construction, given the inclusion of a constant in the VAR. Combining the estimates for the vector $\boldsymbol{\beta}=\left(\beta_{1}, \beta_{2}, \ldots, \beta_{8}\right)^{\prime}$, we get

$$
\hat{\boldsymbol{\beta}} \stackrel{p}{\rightarrow} E\left(\boldsymbol{u}_{t} m_{t}\right) \frac{1}{V\left(m_{t}\right)}=\boldsymbol{b}^{u} \frac{\phi}{V\left(m_{t}\right)}
$$

The equality follows from the fact that, under relevance and exogeneity of the proxy, $E\left(m_{t} \epsilon_{t}^{u}\right)=\phi \neq 0$ and $E\left(m_{t} \epsilon_{t}^{*}\right)=\mathbf{0}$, hence

$$
E\left(\boldsymbol{u}_{t} m_{t}\right)=E\left(\left[\boldsymbol{b}^{u} \epsilon_{t}^{u}+B^{*} \boldsymbol{\epsilon}_{t}^{*}\right] m_{t}\right)=\boldsymbol{b}^{u} E\left(\epsilon_{t}^{u} m_{t}\right)+B^{*} E\left(\boldsymbol{\epsilon}_{t}^{*} m_{t}\right)=\boldsymbol{b}^{u} E\left(\epsilon_{t}^{u} m_{t}\right)=\boldsymbol{b}^{u} \phi
$$

It follows that $\hat{\boldsymbol{\beta}}$ converges to the true impulse vector $\boldsymbol{b}^{u}$, up to a scale. Since this scale is constant across equations, the impulse responses are consistently estimated up to a scale that preserves the relative variations across equations. Last, to recover impulse responses to a one standard deviation shock, we need an estimator for $\boldsymbol{b}^{u}$, not $\boldsymbol{b}^{u} \frac{\phi}{V\left(m_{t}\right)}$. This can be done by getting an estimate of the scaling factor $\frac{\phi}{V\left(m_{t}\right)}$ by exploiting the informations included in the covariance restrictions $\Sigma=B B^{\prime}$. The derivations are 
available on the website of one of the authors. ${ }^{16}$

To estimate the structural shocks, use the fact that

$$
\begin{aligned}
\hat{\Sigma}^{-1} \hat{E}\left(\hat{\boldsymbol{u}}_{t} m_{t}\right) & =\left(\frac{\sum_{t=1}^{T} \hat{\boldsymbol{u}}_{t} \hat{\boldsymbol{u}}_{t}^{\prime}}{T}\right)^{-1} \frac{\sum_{t=1}^{T} \hat{\boldsymbol{u}}_{t} m_{t}}{T} \\
& \stackrel{p}{\rightarrow}\left(B B^{\prime}\right)^{-1} E\left(\boldsymbol{u}_{t} m_{t}\right)=B^{\prime-1} B^{-1} \boldsymbol{b}^{\boldsymbol{u}} \phi=\boldsymbol{a}^{\boldsymbol{u}} \phi
\end{aligned}
$$

where $V\left(\boldsymbol{\epsilon}_{t}\right)$ is normalized to the identity matrix, and $a^{u}$ is the row vector (written as column) of the $A=B^{-1}$ matrix corresponding to the vector $\boldsymbol{b}^{u}$ in $B$. To estimate $a^{u}$ and hence the structural uncertainty shocks, obtain an estimate of $\phi$ from any of the equation in the equality $\hat{E}\left(\hat{\boldsymbol{u}}_{t} m_{t}\right)=\boldsymbol{b}^{u} \phi$, given the estimate for $\boldsymbol{b}^{u}$.

\footnotetext{
${ }^{16}$ https://sites.google.com/site/michelepiffereconomics/VARsWithExtInstruments.pdf.
} 


\section{Additional figures and tables}

Figure D.5: Distribution of the proxy for uncertainty shocks
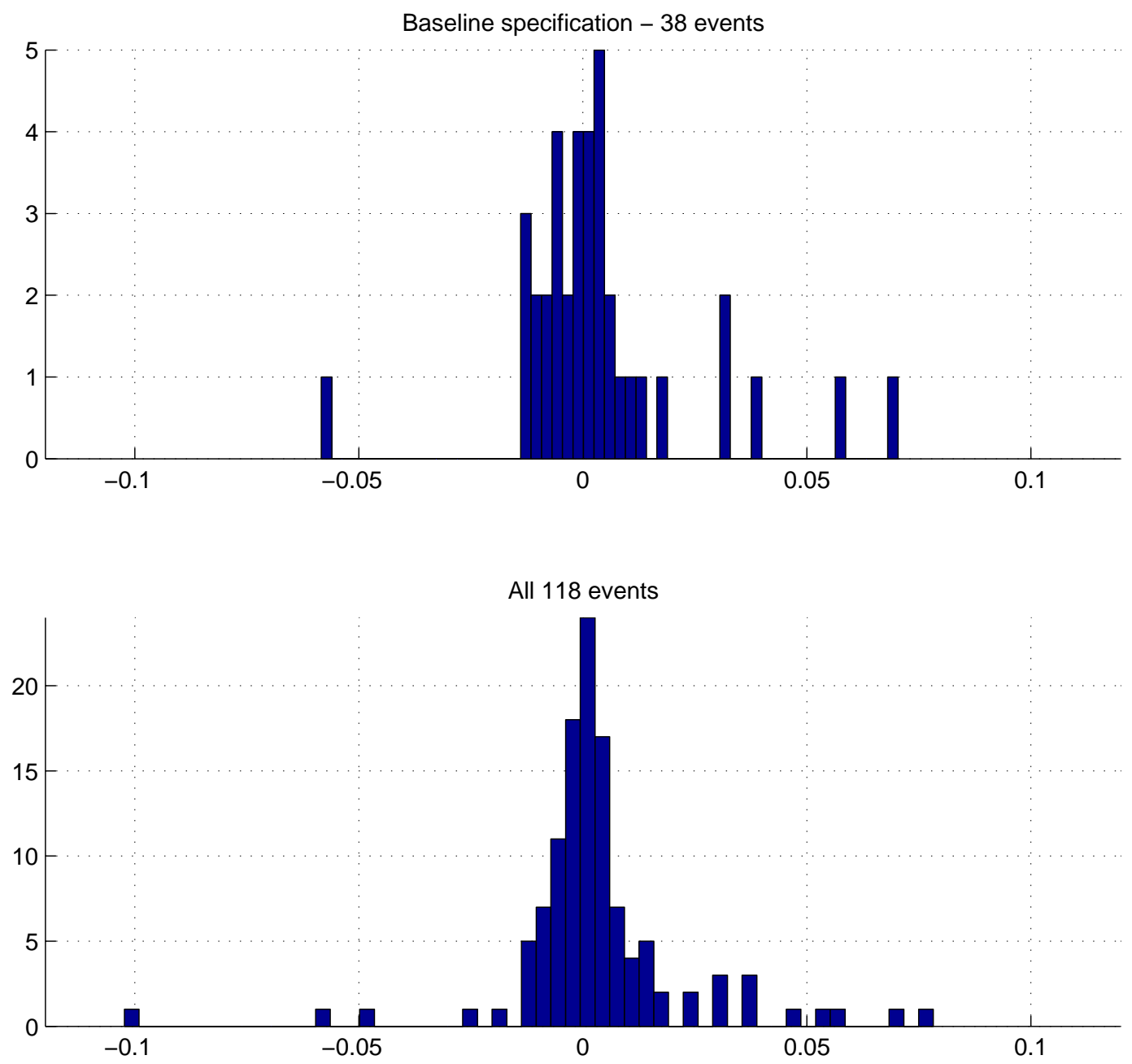

Note: The histogram is computed on the individual events, not on their monthly aggregation. 
Figure D.6: Data used in the baseline specification of the VAR model
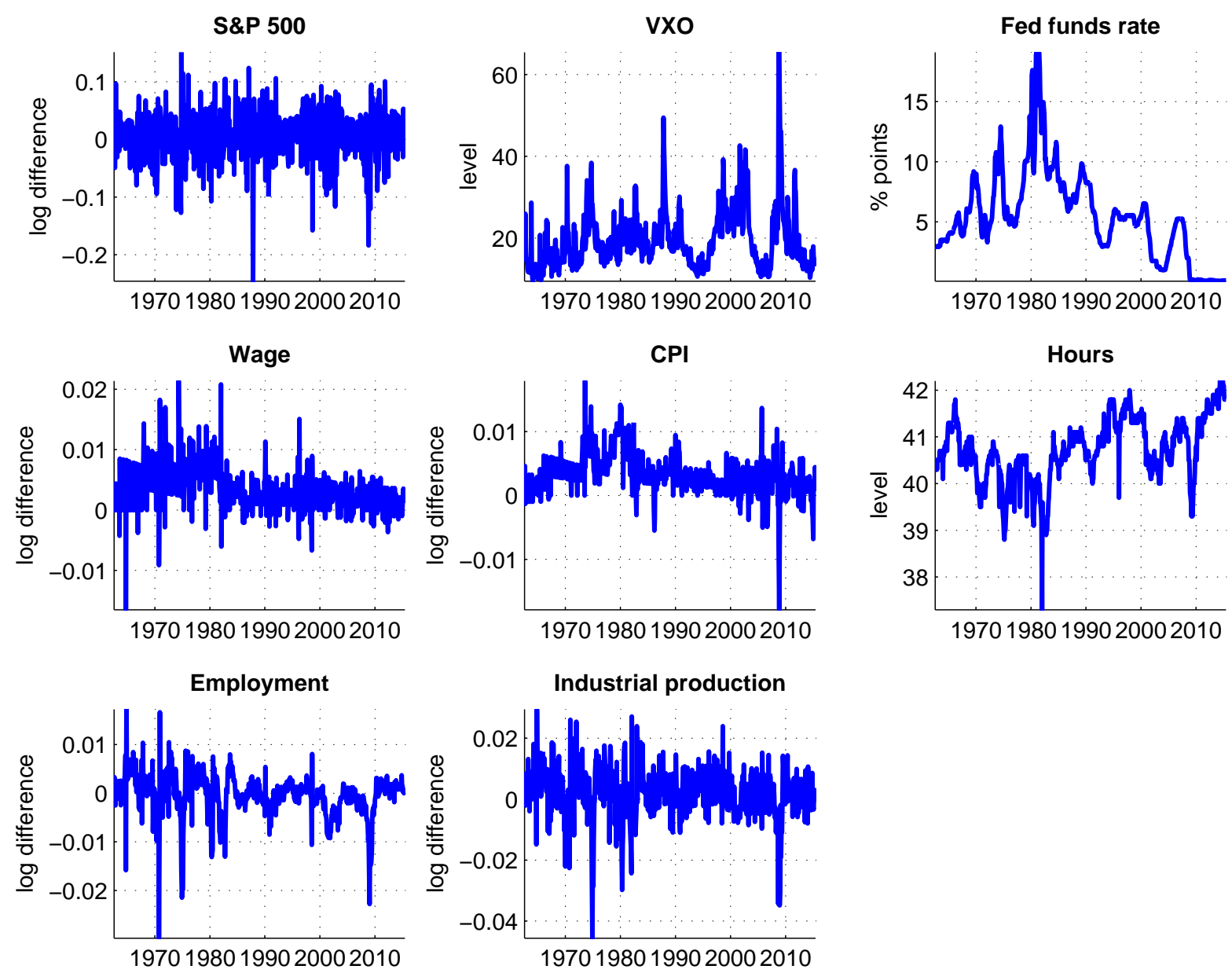

Note: Data plotted as it enters the VAR model: either in levels or in log difference. 
Figure D.7: Impulse responses to an uncertainty shock with all variables expressed as deviations from HP trend
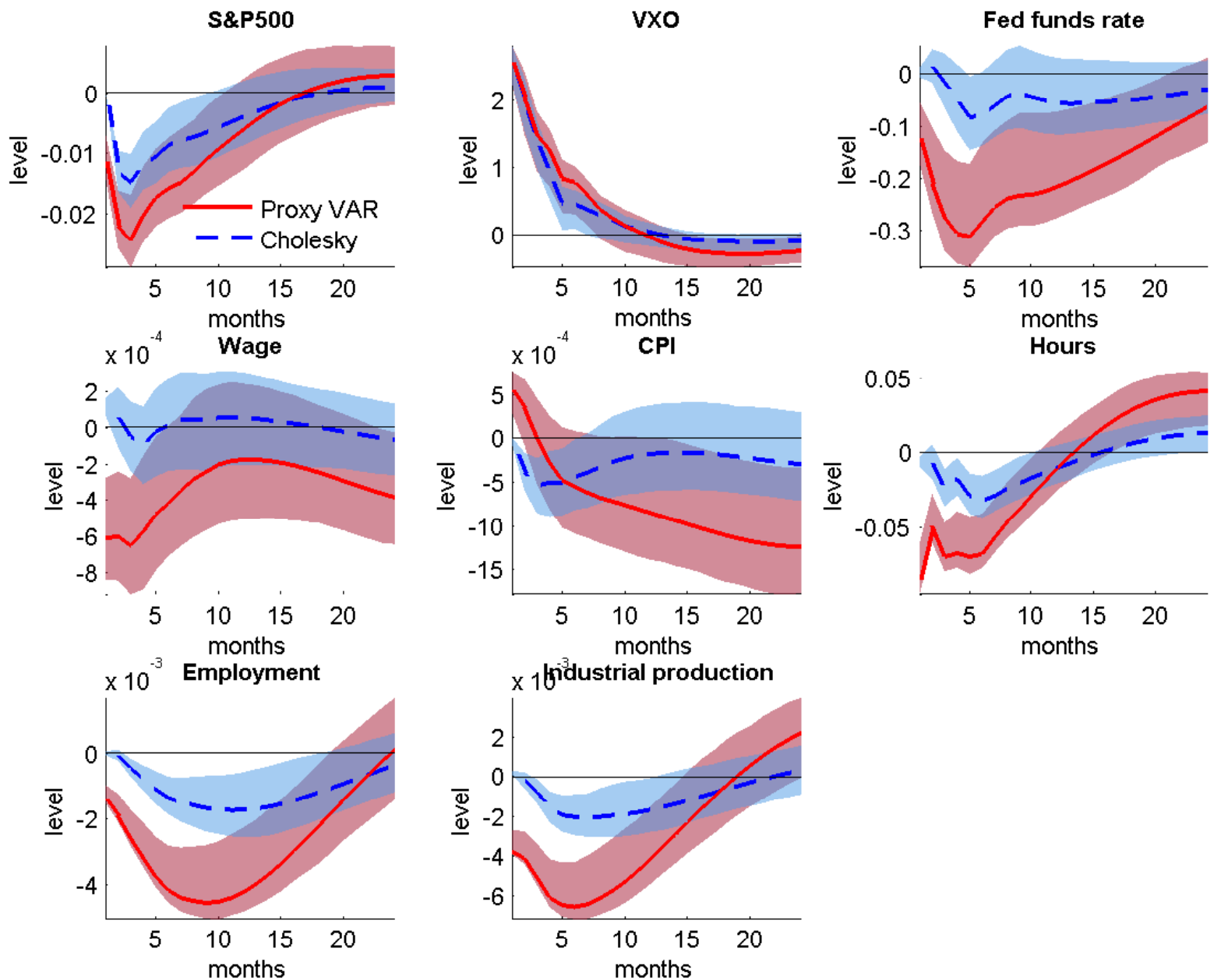

Note: pointwise 90 percent confidence bands reported based on 1000 bootstrap replications. 
Figure D.8: Impulse responses to an uncertainty shock with all variables entering in levels
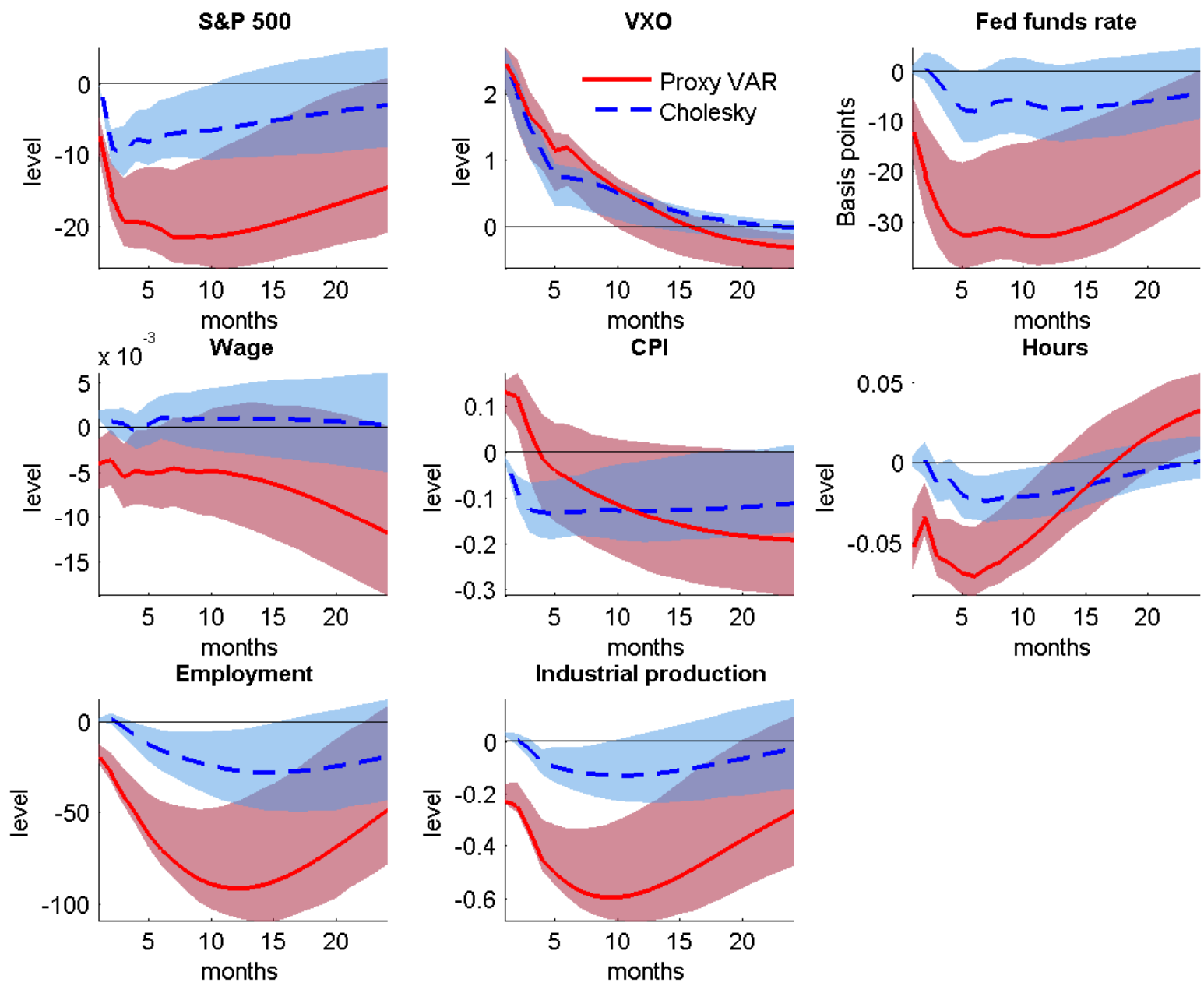

Note: pointwise 90 percent confidence bands reported based on 1000 bootstrap replications. 
Table D.5: Events used in the baseline specification, out of the 117 events collected

\begin{tabular}{|c|c|c|c|}
\hline \# & Date & $\Delta p_{\text {gold }}$ & Event \\
\hline 1 & $04 / 25 / 1980$ & $+7.04 \%$ & Failure of Operation Eagle Claw in the Iranian crisis announced \\
\hline 2 & $09 / 11 / 2001$ & $+5.75 \%$ & $9 / 11$ attack \\
\hline 3 & $09 / 15 / 2008$ & $+3.87 \%$ & AIG asks for lending + Lehman Brothers \\
\hline 4 & 08/02/1990 & $+3.22 \%$ & Iraq invades Kuwait, Gulf War I \\
\hline 5 & $10 / 19 / 1987$ & $+3.06 \%$ & Black Monday \\
\hline 6 & 06/03/1989 & $+1.72 \%$ & Tienanmen Square \\
\hline 7 & $11 / 04 / 1979$ & $+1.39 \%$ & Iran: hostages in US embassy \\
\hline 8 & $07 / 07 / 2005$ & $+1.03 \%$ & London bombing \\
\hline 9 & 08/19/1991 & $+0.84 \%$ & Attempted coup in Moscow \\
\hline 10 & $04 / 29 / 1986$ & $+0.67 \%$ & News of Chernobyl disaster arrived to the West \\
\hline 11 & $09 / 23 / 1998$ & $+0.59 \%$ & LTCM default \\
\hline 12 & $09 / 12 / 2012$ & $+0.35 \%$ & German Court approves ESM \\
\hline 13 & $07 / 21 / 2002$ & $+0.34 \%$ & Worldcom bankruptcy \\
\hline 14 & $09 / 14 / 2007$ & $+0.32 \%$ & Northern Rock receives liquidity support by BoE \\
\hline 15 & $03 / 11 / 1985$ & $+0.26 \%$ & Start of Perestroika, Gorbachev's speech in Leningrad \\
\hline 16 & $10 / 10 / 1980$ & $+0.26 \%$ & Earthquake destroys Algeri \\
\hline 17 & $12 / 21 / 1988$ & $+0.23 \%$ & Lockerbie bombing, Libyan terrorist down the Pan Am Flight \\
\hline 18 & $11 / 13 / 1985$ & $+0.15 \%$ & Volcanic Eruption in Columbia 30.000 dead \\
\hline 19 & $09 / 19 / 1985$ & $+0.13 \%$ & Earthquake in Mexico 15.000 dead \\
\hline 20 & $03 / 11 / 2011$ & $+0.12 \%$ & Fukushima evacuation order \\
\hline 21 & $06 / 10 / 2014$ & $+0.00 \%$ & IS seizes Mosul \\
\hline 22 & $12 / 02 / 2001$ & $-0.09 \%$ & Enron bankruptcy \\
\hline 23 & $04 / 01 / 1982$ & $-0.12 \%$ & Argentina invades Falkland Islands \\
\hline 24 & $11 / 09 / 1989$ & $-0.17 \%$ & Fall of Berlin Wall \\
\hline 25 & $01 / 07 / 2015$ & $-0.27 \%$ & Charlie Hebdo attack \\
\hline 26 & $07 / 05 / 2015$ & $-0.32 \%$ & Greek referendum supports Tsipras \\
\hline 27 & 08/07/1998 & $-0.56 \%$ & US embassy bombing, Kenia and Tanzania \\
\hline 28 & $12 / 07 / 1988$ & $-0.56 \%$ & Earthquake in Armenia 25.000 dead \\
\hline 29 & $07 / 02 / 1997$ & $-0.67 \%$ & Thailand unpegs currency \\
\hline 30 & $11 / 21 / 2013$ & $-0.68 \%$ & Ukraine rejects EU association agreement \\
\hline 31 & $03 / 11 / 2004$ & $-0.71 \%$ & Madrid train bombings \\
\hline 32 & $10 / 17 / 1989$ & $-0.75 \%$ & Loma Prieta earthquake (California) \\
\hline 33 & $03 / 24 / 1989$ & $-0.92 \%$ & Exxon-Valdes hits ground and leaks 40.000 tons of oil \\
\hline 34 & $11 / 09 / 2011$ & $-1.01 \%$ & Berlusconi resignation announced \\
\hline 35 & $05 / 10 / 2010$ & $-1.16 \%$ & EFSF adopted \\
\hline 36 & $04 / 15 / 2013$ & $-1.22 \%$ & Boston marathon bombing \\
\hline 37 & 02/01/1979 & $-1.31 \%$ & Khomeini returns to Tehran \\
\hline 38 & $01 / 26 / 1980$ & $-5.84 \%$ & Israel and Egypt establish diplomatic relations \\
\hline
\end{tabular}

Notes: This table lists the events used in the baseline specification of the model. As discussed, in Section 3, while some events are related to underlying economic or financial phenomena, we do not find any evidence that the the proxy is capturing macroeconomic shocks other than uncertainty shocks. The results are robust to alternative combinations of events used. 
Figure D.9: Impulse responses to an uncertainty shock with uncertainty measure taken from Jurado et al. (2015)
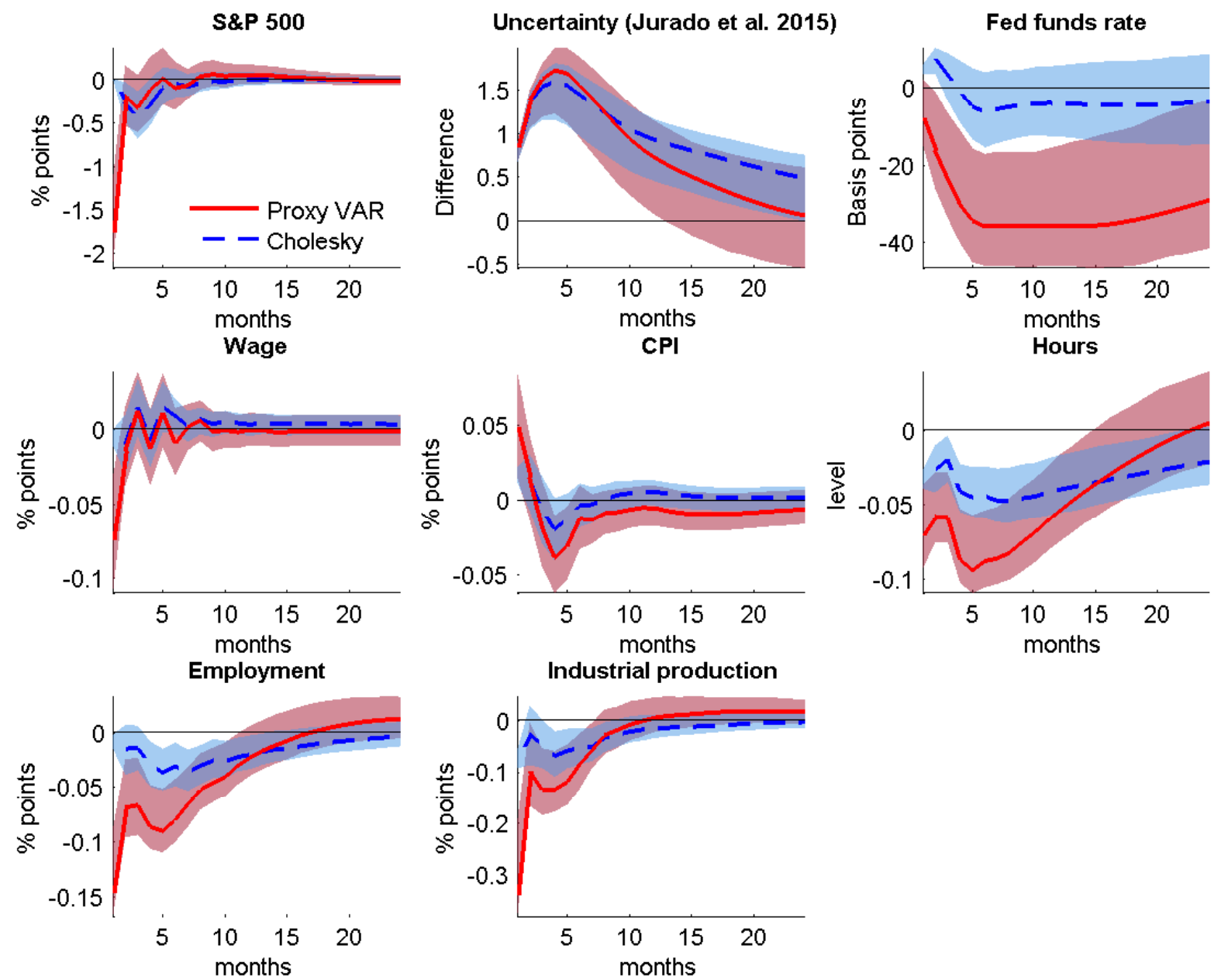

Note: pointwise 90 percent confidence bands reported based on 1000 bootstrap replications. 
Figure D.10: Impulse responses to an uncertainty shock with uncertainty measure taken from Bachmann et al. (2013)
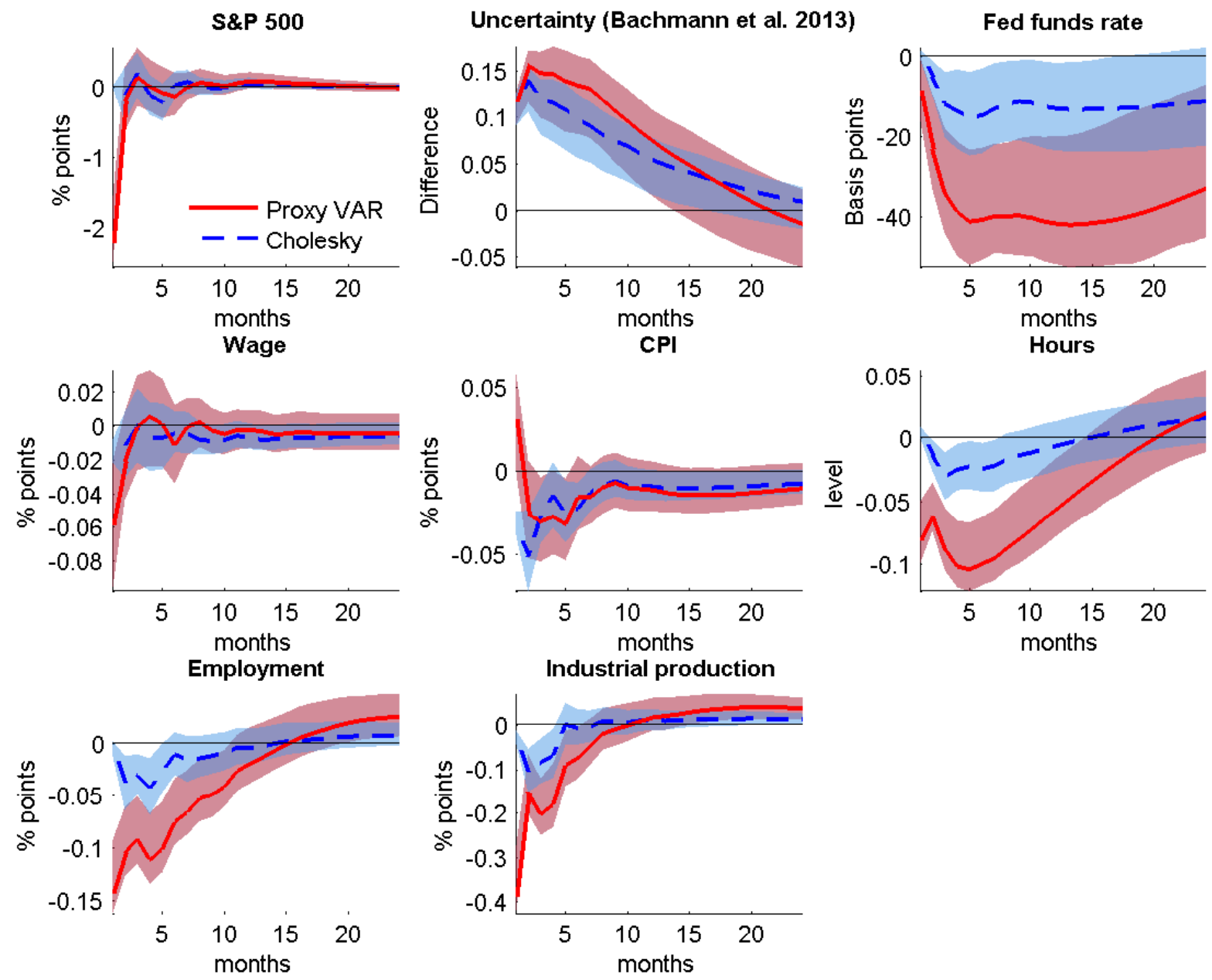

Note: pointwise 90 percent confidence bands reported based on 1000 bootstrap replications. 
Figure D.11: Impulse responses to an uncertainty shock based on VAR(3)
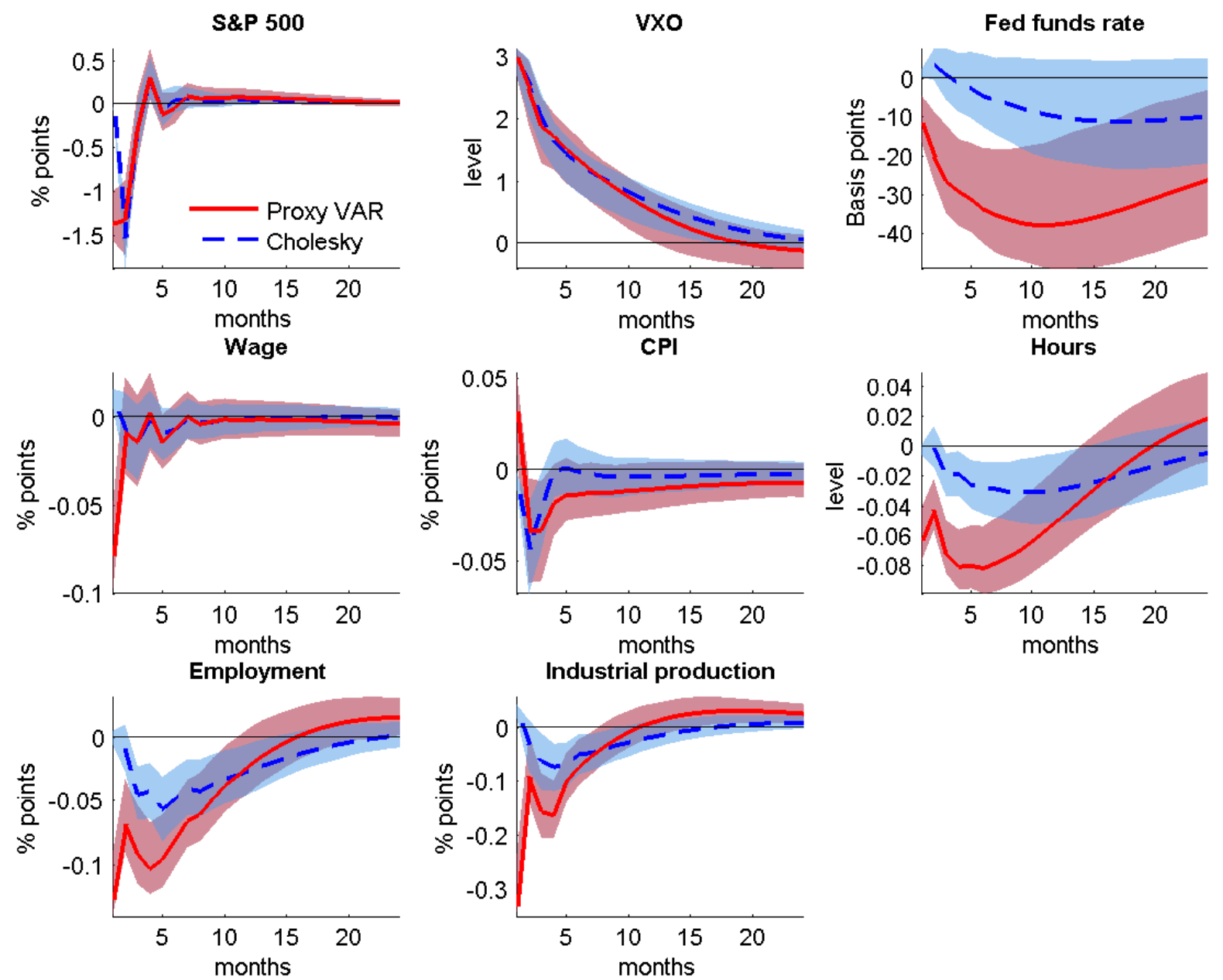

Note: pointwise 90 percent confidence bands reported based on 1000 bootstrap replications. 
Figure D.12: Impulse responses to an uncertainty shock based on VAR(7)
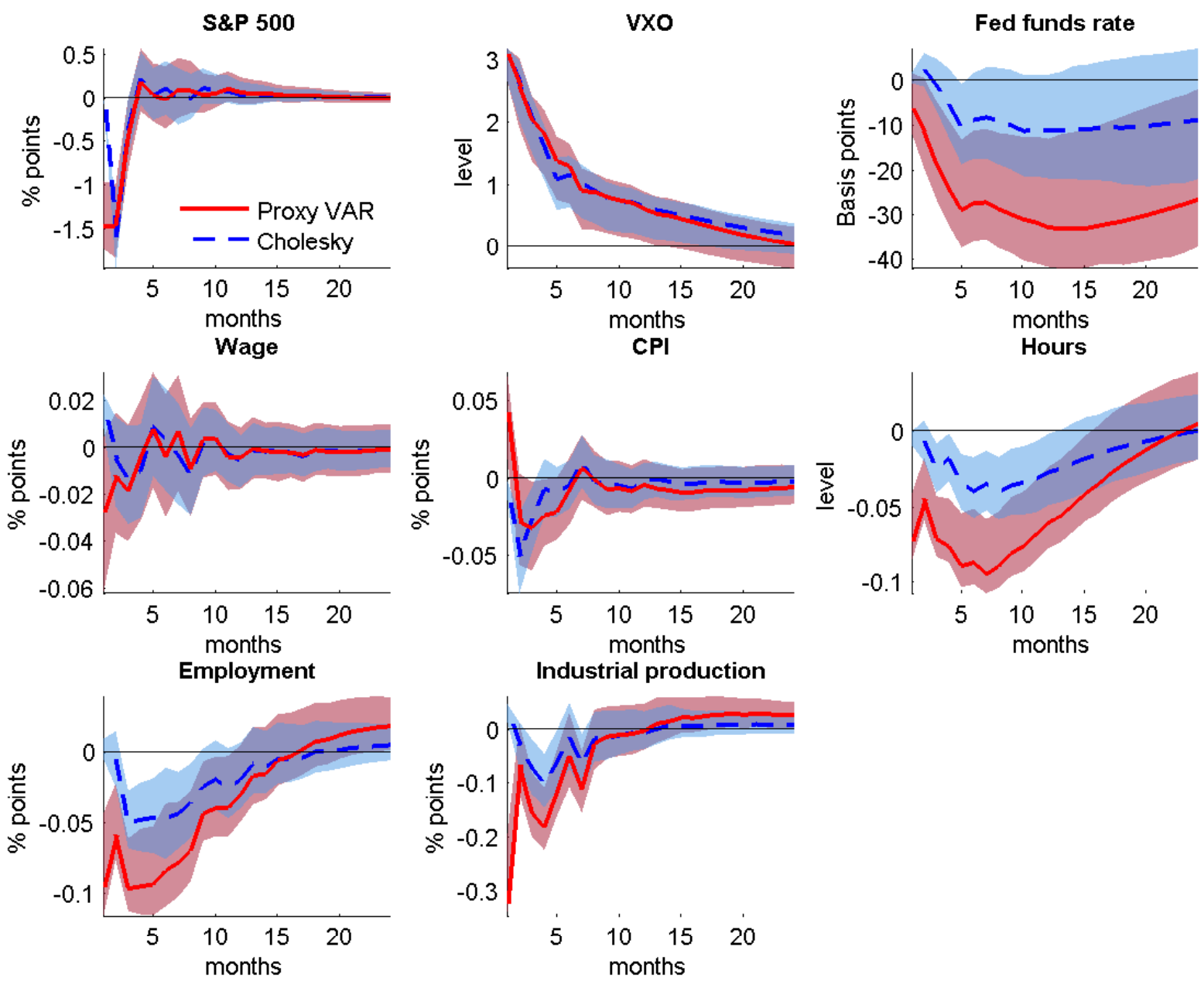

Note: pointwise 90 percent confidence bands reported based on 1000 bootstrap replications. 
Figure D.13: Impulse responses to an uncertainty shock based on proxy variable constructed using all 117 events in the database
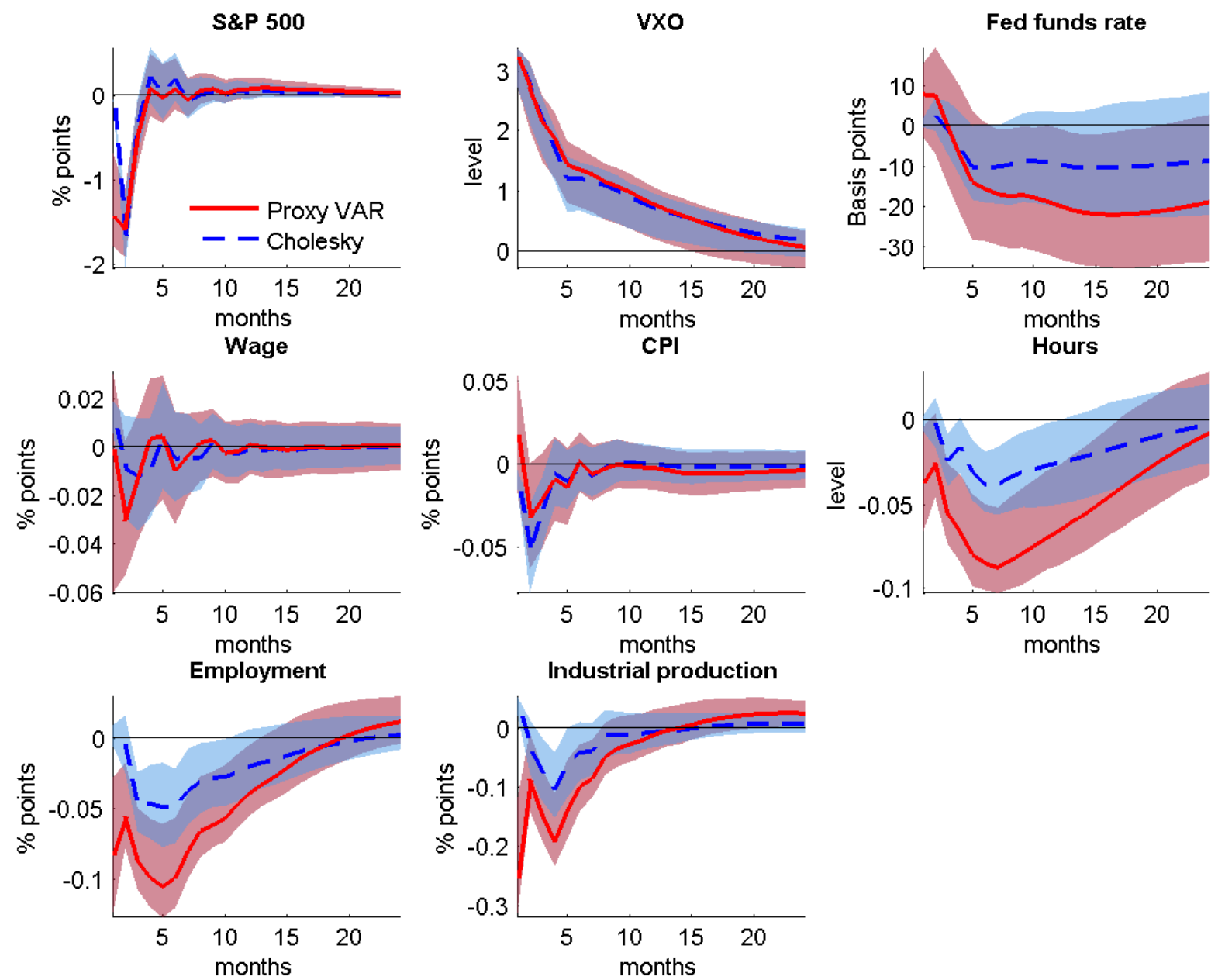

Note: pointwise 90 percent confidence bands reported based on 1000 bootstrap replications. 
Figure D.14: Impulse responses to an uncertainty shock with uncertainty measure ordered first in the recursive SVAR model (and baseline proxy SVAR)
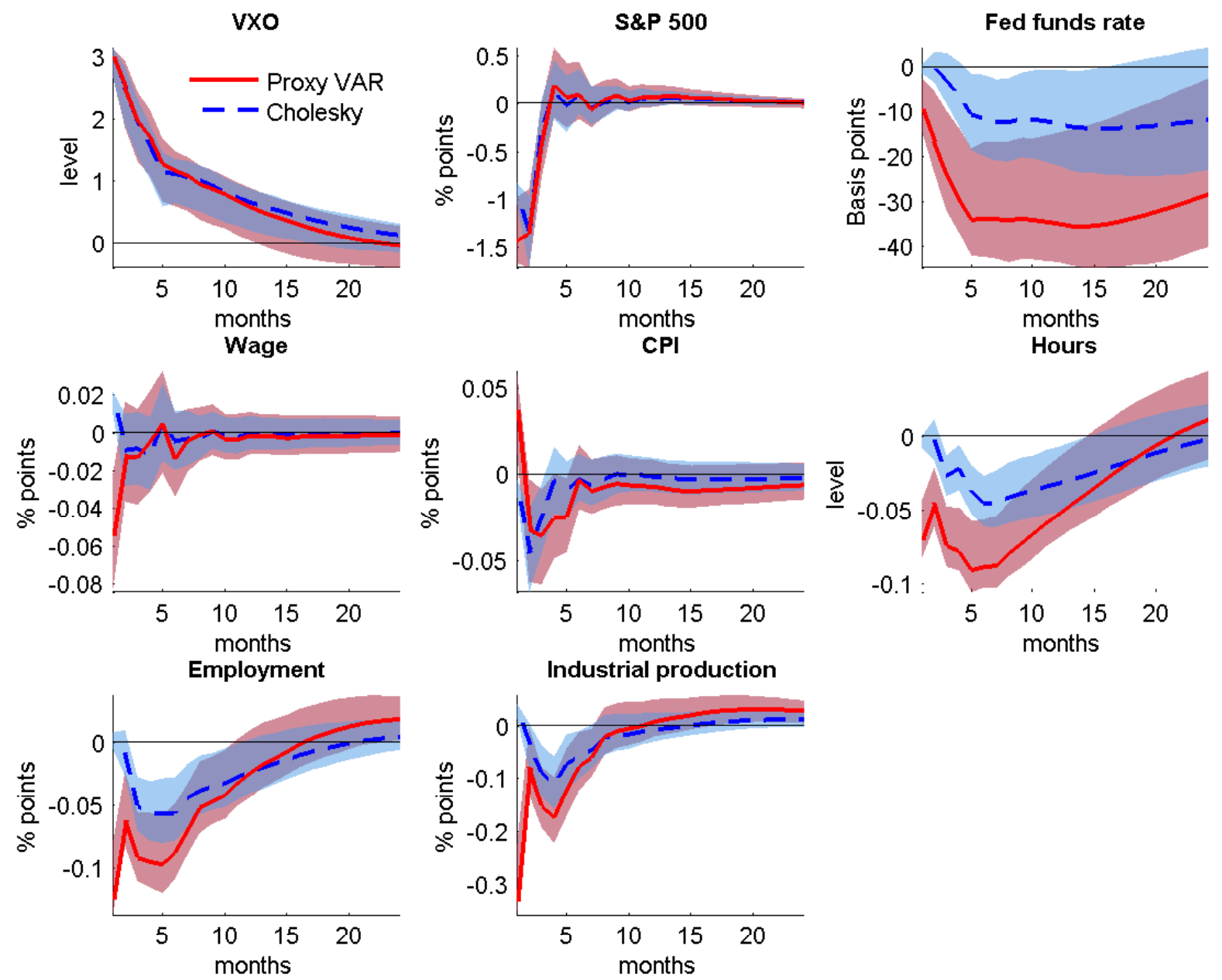

Note: pointwise 90 percent confidence bands reported based on 1000 bootstrap replications. 
Figure D.15: Impulse responses to an uncertainty shock with monthly aggregation of the proxy for uncertainty computed as in Gertler and Karadi (2014))

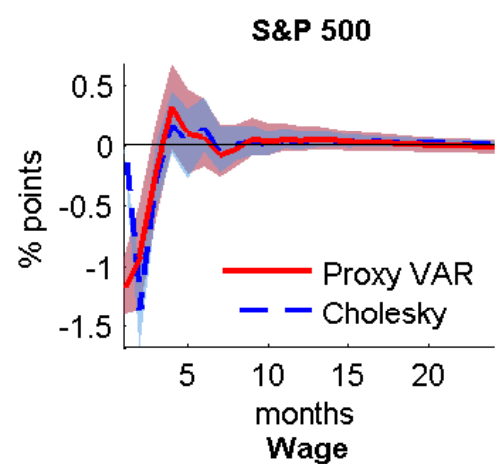

vxo
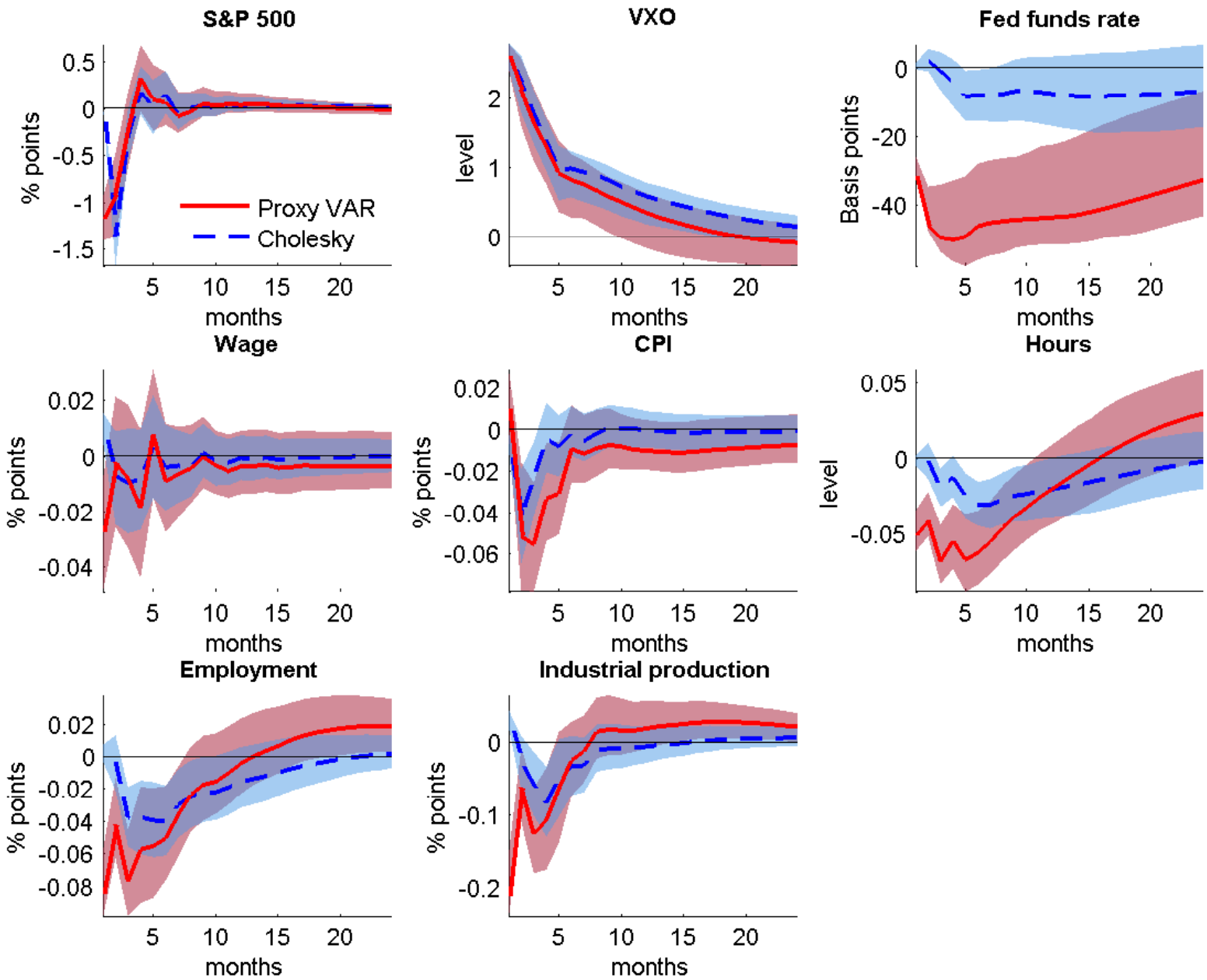

Note: pointwise 90 percent confidence bands reported based on 1000 bootstrap replications. 